\title{
Application of Central Composite Design for Development and Optimization of Eflornithine Hydrochloride-loaded Sustained Release Solid Lipid Microparticles
}

\author{
Ikmeet Kaur Grewal ${ }^{1,2} \mathbb{D}$, Sukhbir Singh ${ }^{1, *}$ (D), Sandeep Arora ${ }^{1}\left(\mathbb{D}\right.$, Neelam Sharma ${ }^{1}$ (D) \\ 1 Chitkara College of Pharmacy, Chitkara University, Punjab, India \\ 2 Department of Pharmacy, Government Medical College, Patiala, Punjab, India \\ * Correspondence: singh.sukhbir12@gmail.com;
}

Scopus Author ID 56402098100

Received: 25.02.2021; Revised: 26.03.2021; Accepted: 30.03.2021; Published: 20.04.2021

\begin{abstract}
Topical application of eflornithine hydrochloride (EFH) is the only available non-hormonal and non-systemic choice available for hirsutism treatment. EFH has low permeability (log P is -2.9). The current investigation's objective is the development of solid lipid microparticles-based sustained topical release delivery with enhanced permeability of eflornithine hydrochloride. EFH-loaded solid lipid microparticles (EFH-SLM) composed of Monecol PC and Softemul 165 using emulsion solvent evaporation technique. The central composite design has been applied to explore an optimized EFHSLM, which was incorporated into cream (EFH-SLM-C) and evaluated for in-vitro drug release and permeation analysis. Design expert software illustrated that an optimized EFH-SLM having desirability function (0.806) could be achieved using 1:3.74 drug: lipid (w/w) (X1), 1.84\% surfactant concentration (X2), and $3.5 \mathrm{~h}$ stirring time (X3), which would illustrate entrapment efficiency (74.97\%), drug loading $(15.84 \%)$, mean diameter $(102.8 \mu \mathrm{m})$ and process yield $(78.07 \%)$. EFH-SLM-C revealed biphasic fickian diffusion release of $16.95 \%$ within $0.5 \mathrm{~h}, 52.31 \%$ in the next $4 \mathrm{~h}$ followed by sustained release of $88.75 \%$ over $24 \mathrm{~h}$. This was confirmed by release exponent $0.411(\mathrm{n}<0.45)$ for Korsmeyer-Peppas. In-vitro steady-state flux $\left(\mathrm{J}_{\mathrm{ss}}\right)\left(\mu \mathrm{gcm}^{-2} \mathrm{~h}^{-1}\right)$ from EFH-C and EFH-SLM-C were 17.27 and 36.65 while apparent permeability coefficient (Papp) $\left(\mathrm{cmh}^{-1}\right)$ was 0.046 and 0.0977 , respectively. EFH-SLM-C could be a promising strategy for augmented permeation and sustained release with minimization of dose, frequency of application, and local adverse effects.
\end{abstract}

Keywords: apparent permeability coefficient; central composite design; eflornithine hydrochloride; Hirsutism; Korsmeyer-Peppas; solid lipid microparticles; sustained release.

(C) 2021 by the authors. This article is an open-access article distributed under the terms and conditions of the Creative Commons Attribution (CC BY) license (https://creativecommons.org/licenses/by/4.0/).

\section{Introduction}

Hirsutism is a highly distressing and relatively common problem in women. Hirsutism is the presence of excess terminal (coarse) hair over the face, chest, stomach, back, upper thighs, or upper arms [1]. Hirsutism is an embarrassing disease that affects the patient physically as well as mentally. Hirsutism can make women extremely self-conscious, threatening both their sense of femininity and self-esteem. All the sufferers want to get rid of this disease at any cost. They are using the existing treatments without considering their side effects; therefore, new techniques need to be explored [2]. Available alternatives for hirsutism treatment include androgen suppression, peripheral androgen blockade, mechanical or cosmetic removal of unwanted hairs, and topical application of eflornithine hydrochloride cream [3]. Androgen suppression could be achieved using oral contraceptives but produces 
certain side effects like suppression of luteinizing and follicle-stimulating hormones, leading to a decrease in ovarian and adrenal androgen production [4]. Another alternative is receptor blockers, but they have the teratogenic potential [5]. Mechanical or cosmetic removal of unwanted hairs through bleaching, shaving, or chemical depilation possibly will be helpful to eliminate unwanted hairs [6] temporarily. Nevertheless, plucking and waxing can cause skin irritation and scarring, while shaving may be psychologically unacceptable and lead to blunt hair. Chemical depilatories might cause skin irritation and electrolysis may be painful, and short-wave diathermy can cause scarring.

Looking towards these drawbacks, topical application of eflornithine hydrochloride seems to be an appropriate preference to eliminate Hirsutism. Eflornithine hydrochloride $(\mathrm{EFH})$ is the only non-hormonal and non-systemic prescription option available for women who suffer from Hirsutism. Application of EFH topical cream is approved by the food and drug administration to treat unwanted facial hair growth. EFH inhibits the L-ornithine decarboxylase enzyme activity, which decreases the production of spermidine protein, which regulates hair growth and differentiation [7]. However, EFH has poor permeability characteristics $(\log \mathrm{P}$ is approximately -2.9); therefore, frequent application of topical cream containing a high percentage of EFH is required to successfully treat Hirsutism. Though continuous use of EFH topical cream may cause local side effects such as irritation, acne, skin itching, stinging, burning, and rashes. Other challenges with conventional topical formulation include the need for a very high dosage, high frequency of applications, short remission period of eight weeks, and post-application skin scaling.

Lipid-based carriers like solid lipid microparticles (SLM) can target and prolonged drug release to hair follicles due to enhanced drug penetration via skin layers [8-17]. Therefore, SLM would be an even more promising strategy for the treatment of Hirsutism [18]. The proven safety and efficacy of lipid-based carriers like Monecol PC (cetyl palmitate) and Softemul 165 (PEG 100 glyceryl stearate) make them attractive candidates for preparing lipid-based formulations in current research [19, 20]. Consequently, the objectives of this study were to formulate a novel eflornithine hydrochloride-loaded solid lipid microparticles (EFH-SLM) composed of Monecol PC and Softemul 165 using emulsion solvent evaporation technique for the treatment of Hirsutism which would enhance permeation along with minimization of dose and frequency of application and therefore, reduced local adverse effects such as irritation, acne, skin itching, stinging, burning and rashes. Central composite design (CCD) has been applied to inspect the influence of formulation and processing variables on response parameters. An optimum batch of EFH-SLM having the greatest entrapment efficiency, drug loading, and process yield, while the least mean diameter was explored using CCD. The optimized EFH-SLM was characterized by x-ray diffraction, dynamic light scattering, and scanning electron microscopy. The optimized EFH-SLM was incorporated into topical cream dosage form and evaluated for physical appearance, spreadability, $\mathrm{pH}$ value, viscosity, thermodynamic stability, percentage drug content, in-vitro drug release, the kinetics of drug release, and in-vitro permeation data analysis.

\section{Materials and Methods}

\subsection{Materials.}

Eflornithine hydrochloride (CAS NO: 68278-23-9) was procured from Rusan Pharma Ltd., Mumbai, India. Monecol PC and Softemul 165 were procured from Mohini Organics 
Private Limited (Mumbai, India). Tween 20 (PEG-20 sorbitan monolaurate, HLB 16.7), potassium dihydrogen phosphate, sodium hydroxide, and D-mannitol were procured from Loba Chemie Pvt. Ltd., Mumbai, India. Dialysis membrane was purchased from Himedia Laboratories, Mumbai, India. All other utilized chemicals were of analytical grade.

\subsection{Experimental design.}

The central composite design was used to systemically investigate the influence of independent variables over-dependent parameters specified in Table 1. Twenty batches of SLM were synthesized according to the design outline generated by Stat-Ease Design-Expert software version 11.1.2.0 (Table 2). Second-order polynomial models were developed for analyzing main, interaction, and quadratic effects of factors over dependent variables [19, 21]:

$$
Y=\beta_{0}+\sum_{i=1}^{3} \beta_{i} X_{i}+\sum_{\mathrm{i}=1}^{2} \sum_{\mathrm{j}=\mathrm{i}+1}^{3} \beta_{\mathrm{ij}} X_{\mathrm{i}} X_{\mathrm{j}}+\sum_{\mathrm{i}=1}^{3} \beta_{\mathrm{ii}} X_{\mathrm{i}}^{2}+\epsilon \quad \text { Eq. (1) }
$$

Where $Y$ denotes the observed response variable, $\beta_{0}$ is constant-coefficient, and $\epsilon$ is residually correlated to experiments. $\beta_{\mathrm{i}}, \beta_{\mathrm{ii}}$, and $\beta_{\mathrm{ij}}$ represent coefficients of linear, quadratic parameter, and interaction parameters, respectively. $X_{\mathrm{i}}$ represents the average outcome of changing one variable at a time from low to high; polynomial terms $X_{i}^{2}$ were employed to assess the nonlinearity effect of variable $X_{i}$, interaction terms $X_{\mathrm{i}} X_{j}$ illustrated how the response transformed when two variables $X_{i}$ and $X_{j}$ were altered concurrently [22-25].

Table 1. Independent and dependent variables used in central composite design.

\begin{tabular}{l|l|l|l|l|l}
\multirow{2}{*}{ Independent variables } & Coded levels of variables & $\mathbf{+ 1}$ & $\mathbf{+ 1 . 6 8}(+\boldsymbol{\alpha})$ \\
\cline { 2 - 6 } & $\mathbf{- 1 . 6 8 ( - \alpha )}$ & $\mathbf{- 1}$ & $\mathbf{0}$ & $\mathbf{1}$ \\
\hline$X_{1}=$ Drug: lipid $(\mathrm{w} / \mathrm{w})$ & $1: 1.32$ & $1: 2$ & $1: 3$ & $1: 4$ & $1: 4.68$ \\
\hline$X_{2}=$ Surfactant concentration $(\% \mathrm{v} / \mathrm{v})$ & 0.16 & 0.5 & 1 & 1.5 & 1.84 \\
\hline$X_{3}=$ Stirring time $(\mathrm{h})$ & 1.32 & 2 & 3 & 4 & 4.68 \\
\hline Dependent variables & \multicolumn{5}{|c}{ Constraints } \\
\hline$Y_{1}=$ Entrapment efficiency $(\% \mathrm{w} / \mathrm{w})$ & \multicolumn{5}{|c}{ Maximizizize } \\
\hline$Y_{2}=$ Drug loading $(\% \mathrm{w} / \mathrm{w})$ & \multicolumn{5}{|c}{ Maximizizize } \\
\hline$Y_{2}=$ Mean diameter $(\mu \mathrm{m})$ & \multicolumn{5}{|c}{}
\end{tabular}

Table 2. Central composite experimental design matrix with coded value.

\begin{tabular}{|c|c|c|c|c|}
\hline Run & $\mathrm{X}_{1}$ (Drug: lipid) (w/w) & $\mathrm{X}_{2}($ Surfactant concentration) $(\% \mathrm{v} / \mathrm{v})$ & $\mathbf{X}_{3}$ (Stirring time) (h) & Design \\
\hline 1 & -1 & -1 & -1 & \multirow{8}{*}{$\begin{array}{l}\text { Factorial } \\
\text { Design }\end{array}$} \\
\hline 2 & 1 & -1 & -1 & \\
\hline 3 & -1 & 1 & -1 & \\
\hline 4 & 1 & 1 & -1 & \\
\hline 5 & -1 & -1 & 1 & \\
\hline 6 & 1 & -1 & 1 & \\
\hline 7 & -1 & 1 & 1 & \\
\hline 8 & 1 & 1 & 1 & \\
\hline 9 & -1.68 & 0 & 0 & \multirow{6}{*}{$\begin{array}{l}\text { Axial } \\
\text { Points }\end{array}$} \\
\hline 10 & 1.68 & 0 & 0 & \\
\hline 11 & 0 & -1.68 & 0 & \\
\hline 12 & 0 & 1.68 & 0 & \\
\hline 13 & 0 & 0 & -1.68 & \\
\hline 14 & 0 & 0 & 1.68 & \\
\hline 15 & 0 & 0 & 0 & \multirow{6}{*}{$\begin{array}{l}\text { Center } \\
\text { points }\end{array}$} \\
\hline 16 & 0 & 0 & 0 & \\
\hline 17 & 0 & 0 & 0 & \\
\hline 18 & 0 & 0 & 0 & \\
\hline 19 & 0 & 0 & 0 & \\
\hline 20 & 0 & 0 & 0 & \\
\hline
\end{tabular}




\subsection{Production of solid lipid microparticles of eflornithine hydrochloride (EFH-SLM).}

EFH-SLM was manufactured via emulsion-solvent evaporation technique in conjunction with ultrasonication. Briefly, accurately weighed amount of Monecol PC and Softemul 165 were melted at $60^{\circ} \mathrm{C}$, and $5 \mathrm{~mL}$ solution of EFH in acetone-ethanol (1:1) mixture was transferred to molten lipids to produce organic phase. Subsequently, the organic phase was transferred slowly through a syringe into an aqueous phase containing PEG-20 sorbitan monolaurate as surfactant with continuous magnetic stirring at $37 \pm 0.50 \mathrm{C}$ at $2000 \mathrm{rpm}$ (Remi, India). The resulting pre-emulsion was ultrasonicated for ten minutes using an ultrasonic probe sonicator (PCI analytical, India) to fabricate an oil-water microemulsion cooled with continuous magnetic stirring at room temperature till complete evaporation of organic solvent to generate EFH-SLM dispersion. Lyophilization was accomplished under vacuum $(0.5 \mathrm{kPa})$ at $-65 \mathrm{oC}$ for $24 \mathrm{~h}$ using D-mannitol (lyoprotectant) in a freeze dryer (Allied Frost, India) [20, 26-30].

\subsection{Determination of EFH-SLM response variables $\left(Y_{I^{-}} Y_{4}\right)$.}

2.4.1. Entrapment efficiency (Y1) and drug loading (Y2) determination.

Entrapment efficiency and drug loading of EFH-SLM were determined using the ultrafiltration method [21,31]. The amount of drug entrapped was determined based on free drug concentration in EFH-SLM. Briefly, accurately weighed amount of EFH-SLM was ultrafiltered via filter membrane (Himedia, India), and ultra-filtrate was diluted with phosphate buffer, pH 6.8 and drug content (Free EFH) in solution was analyzed using spectrophotometer technique through derivatization with dansyl chloride using double beam UV-visible spectrophotometer at $243 \mathrm{~nm}$ (Systronics AU-2701, Ahmedabad, India) [32,33]. Percentage $\mathrm{EE}$ and DL of EFH-SLM was calculated based on the following equations:

$$
\begin{array}{ll}
\% \mathrm{EE}, \mathrm{w} / \mathrm{w}=\frac{\text { Weight of EFH added-Free } \mathrm{EFH}}{\text { Weight } \text { of } \mathrm{EFH} \text { added }} \times 100 & \text { Eq. (2) } \\
\% \mathrm{DL}, \mathrm{w} / \mathrm{w}=\frac{\text { Weight of } \mathrm{EFH} \text { added-Free } \mathrm{EFH}}{\text { Weight of lipids added }} \times 100 & \text { Eq. (3) }
\end{array}
$$

2.4.2. Determination of mean diameter $\left(\mathrm{Y}_{3}\right)$ of EFH-SLM.

The mean diameter of EFH-SLM was determined by optical microscopy employing an optical microscope. All samples were diluted with distilled water, and a thin film of diluted EFH-SLM was applied on a microscope slide to examine under a light microscope. Measurement was conducted in triplicates to acquire mean diameter [31-34].

2.4.3. Determination of $\%$ process yield $\left(\mathrm{Y}_{4}\right)$.

The completely dried EFH-SLM recovered from each experimental run was accurately weighed. The percentage process yield of SLM was calculated using the following equation [35].

$$
\% \text { Process Yield, } \mathrm{w} / \mathrm{w}=\frac{\text { Weight of EFH-SLM }}{\text { Initial weight of EFH+Lipids }} \times 100
$$




\subsection{Optimized and validation of EFH-SLM batch by numerical optimization method.}

A mathematical relationship among independent and response parameters was generated by response surface regression analysis, and optimum values of variables were estimated using Design-Expert software [21]. Subsequently, an additional batch of EFH-SLM was produced using predicted values of parameters to confirm the optimization approach. Response variables $\left(Y_{1}-Y_{4}\right)$ for an additional batch of EFH-SLM were experimentally determined as per the abovementioned procedures. The percentage bias was calculated for comparing experimental values with model predicted values using the following equation for validating the optimization strategy [36].

$$
\% \text { Bias }=\frac{\text { Predicted value-Experimental value }}{\text { Predicted value }} \times 100
$$

\subsection{Characterization of optimized EFH-SLM.}

\subsubsection{X-ray diffraction (XRD).}

X-ray diffraction patterns were acquired on Xpert-Pro diffractometer in continuous scan mode over an angular range from $5-50^{\circ}$ at $2 \theta$ scale using $1.54 \mathrm{~A}^{\circ} \mathrm{CuK} \alpha$ radiation and 1.39 $\mathrm{A}^{\circ} \mathrm{CuK} \beta$ radiations produced through tube activated at $45 \mathrm{kV}, 40 \mathrm{~mA}$.

\subsubsection{Dynamic light scattering (DLS).}

Mean diameter and Polydispersity index (PDI) of EFH-SLM were assessed using dynamic light scattering technique using Beckman Coulter, Version 3.73/2.30 (USA). Briefly, $20 \mathrm{mg}$ of EFH-SLM was dispersed in distilled water $(2 \mathrm{~mL})$ in a quartz cuvette and analyzed at $25^{\circ} \mathrm{C}$.

\subsubsection{Scanning electron microscopy (SEM).}

The morphological characteristics, as well as the shape of lyophilized EFH-SLM, were recorded with Jeol JSM6100 (Japan). EFH-SLM was placed on an aluminum stub with doublesided adhesive tape, layered by $20 \mathrm{~nm}$ gold films through sputtering, and observed at $1.4 \mathrm{kV}$.

\subsection{Manufacturing of optimized EFH-SLM loaded topical cream.}

An oil phase was produced through melting the hard paraffin and beeswax at $75^{\circ} \mathrm{C}$, followed by the addition and gentle mixing of liquid paraffin, cetyl alcohol, stearyl alcohol, cetyl palmitate, and isopropyl myristate. The aqueous phase was prepared by dissolving the tween 80 , span 60 , and propylparaben in distilled water and heated to $75-80^{\circ} \mathrm{C}$ for complete dissolution. The aqueous phase was shifted to the oil phase for emulsification which was cooled to room temperature under constant stirring. An optimized EFH-SLM was incorporated in a pre-prepared cream base with moderate stirring for 10 min to produce microparticles loaded cream (EFH-SLM-C). Likewise, creams incorporating eflornithine hydrochloride (EFH-C) and physical mixture (PM) (EFH-PM-C) were manufactured [37-42]. 


\subsection{Evaluation of optimized EFH-SLM loaded topical cream (EFH-SLM-C).}

2.8.1. Physical appearance, Spreadability, $\mathrm{pH}$ value, and viscosity determination.

EFH-SLM-C was visually checked for color consistency, homogeneity, and texture. Homogeneity and texture were assessed by rubbing the small amount of cream amid the thumb and index finger. Instant skin sensation like grittiness, stiffness, and greasiness was also examined [43, 44]. The spreadability was based on the measurement of sample spreading diameter of one gram cream among two horizontal glass plates. The standard weight on the top surface was twenty-five grams for one minute. For $\mathrm{pH}$ testing, a small amount of EFH-SLM$\mathrm{C}$ was dispersed in distilled water and analyzed using a previously calibrated $\mathrm{pH}$ meter. The prepared EFH-SLM-C was investigated for rheology using Brookfield rotational digital viscometer model LVDV-II+P, the USA at $25 \pm 2{ }^{\circ} \mathrm{C}$ equipped with LV-spindle-64 at different shear rates. All measurements were taken in triplicate and represented as mean \pm SD [45-51].

\subsubsection{Thermodynamic stability.}

Two experiments were carried out to investigate the thermal stability of formulated EFH-SLM-C. EFH-SLM-C has been centrifuged around 6,000 rpm for $30 \mathrm{~min}$ in the centrifuge stress test and after that inspected for phase separation. In the freeze-thaw period testing period, EFH-SLM-C was exposed to a minimum of three comprehensive freeze-thaw intervals, every 24 hours at $25^{\circ} \mathrm{C}$ accompanied with 24 hours at $-5{ }^{\circ} \mathrm{C}$ [47].

\subsubsection{Percentage drug content.}

One gram of EFH-SLM-C was taken into a standard volumetric flask and mixed with a mixture of phosphate buffer, $\mathrm{pH}$ 6.8. The sample was analyzed spectrophotometrically at 243 $\mathrm{nm}$ after filtration through a Millipore filter $(0.45 \mu \mathrm{m})$ to estimate the drug content [46].

\subsubsection{In-vitro drug release study.}

Dialysis membrane having 12,000-14,000 Da molecular weights (Himedia, India) was drenched in distilled water for twelve hours and mounted between the cell compartments of Franz diffusion cell [52]. The surface area of the release membrane was $2.54 \mathrm{~cm}^{2}$. The acceptor compartment was filled with $20 \mathrm{~mL}$ phosphate buffer, $\mathrm{pH} 6.8$ as receptor medium, and agitated at $200 \mathrm{rpm}$ via the magnetic bar in the acceptor medium to reduce the stagnated surfaces. $\mathrm{EFH}-$ C, EFH-SLM-C, and EFH-PM-C (containing approximately $7.5 \mathrm{mg} \mathrm{EFH)} \mathrm{were} \mathrm{applied} \mathrm{to} \mathrm{the}$ dialysis membrane facing the donor compartment. During the experiments, the temperature of the Franz diffusion cell chamber, the solution on the receptor side, was maintained at $37 \pm 0.5^{\circ} \mathrm{C}$. Approximately $0.5 \mathrm{~mL}$ samples were removed from the acceptor compartment at $0.5,1,2,4$, $6,8,12$, and $24 \mathrm{~h}$ and spectroscopically analyzed at $243 \mathrm{~nm}$. An equivalent amount of medium was transferred to the cell through the side tube $[53,54]$. Experiments of release analysis were replicated three times.

\subsubsection{Permeation data analysis.}

The total quantity $(\mathrm{Q})(\mu \mathrm{g})$ permeated by the dialysis membrane was determined by multiplying the drug's accumulated concentration $\left(\mu \mathrm{gmL}^{-1}\right)$ in the receptor chamber and its receptor chamber volume $(\mathrm{mL})$. Using GraphPad Prism®software, the slope of the linear portion of the curve among the amount of drug permeated per unit area $\left(\mu \mathrm{gcm}^{-2}\right) v s$. time $(\mathrm{h})$ 
was obtained. Steady-state flux $\left(J_{s s}\right)\left(\mu \mathrm{gmin}^{-1}\right)$ was determined by dividing the slope with membrane surface area. The apparent permeability coefficient $\left(P_{\mathrm{app}}\right)$ was computed using the following equation $[50,52,55]$.

$$
\begin{array}{ll}
J_{s S}=\frac{\mathrm{dQ} / \mathrm{dt}}{\mathrm{A}} & \text { Eq. (6) } \\
P_{a p p}=\frac{J_{\mathrm{sS}}}{C_{\mathrm{d}}} & \text { Eq. (7) }
\end{array}
$$

2.8.6. Release kinetics.

In-vitro dissolution kinetic models like zero-order, first-order, Higuchi and KorsmeyerPeppas, have been implemented to illustrate the drug release phenomenon from EFH-SLM-C. In Korsmeyer-Peppas kinetics, the release exponent value $<0.45,0.46-0.88,0.89$, and $>0.89$, respectively, corresponds to fickian diffusion, anomalous diffusion, case II transport, and super case II transport [56].

\subsection{Statistical analysis.}

The statistical analysis of polynomial equations was performed using the analysis of variance (ANOVA) through Design-Expert software (Trial Version 11.1.2.0, Stat-Ease Inc., $\mathrm{MN}$ ). All other data were analyzed using ANOVA followed by Bonferroni post-test using GraphPad Prism version 6.01 (GraphPad Software, San Diego, California, USA). The statistical difference was considered significant $(p<0.05)$. All the results were shown as the average \pm standard deviation.

\section{Results and Discussion}

\subsection{Entrapment efficiency $(\% E E)\left(Y_{1}\right)$.}

The values of EE for twenty batches of EFH-SLM ranged from 46.33 to $75.66 \%$ w/w. A lipid drug delivery system must be capable of entrapping the utmost possible quantity of drug with a minimum amount of lipid; therefore, optimum drug: lipid for the highest \% EE should be acquired. The effect of design variables on \%EE can be described by second-order polynomial Eq. (8).

$$
\begin{array}{ccc}
Y_{1}=70.20+9.26 X_{1}+0.56 X_{2}+1.64 X_{3}+1.21 X_{1} X_{2}+0.51 X_{1} X_{3}-1.07 X_{2} X_{3}-3.53 X_{1}^{2}- \\
0.746 X_{2}^{2}-2.41 X_{3}^{2} & \left(r^{2}=0.9807\right) & \text { Eq. (8) }
\end{array}
$$

Model $F$-value and lack of fit $F$-value for $\%$ EE was found $56.55(p<0.0001)$ and 1.68 $(p>0.05)$, respectively, which implies significant model fitting and non-significant lack of fitting indicating the accuracy of data. The correlation coefficient $\left(r^{2}=0.9807\right)$ for the polynomial quadratic equation revealed significant data fitting in the model. $X_{1}, X_{2}$ and $X_{3}$ regression coefficients have positive signs, which illustrated that \% EE of EFH-SLM increased with increasing values of these design variables. The factors affecting $\%$ EE with strong linear effect were $X_{1}(F$-value, 403.55$)$ and $X_{3}(F$-value, 12.62$)(p<0.05) . X_{1}(F$-value, 61.84$)$ and $X_{3}$ $(F$-value, 28.94) had significant quadratic influence $(p<0.05)$ (Table 3$)$. Drug: lipid directly augmented drug entrapment in EFH-SLM, which might be attributable to increased viscosity of droplets incorporating an immense amount of drug. Moreover, the viscous solution produces a barrier that could decrease the diffusion of EFH from the organic phase into an external aqueous phase. Furthermore, an increasing amount of lipid would produce larger particles of greater capacity to entrap a huge amount of drug (Figure 1) [21, 22, 57, 58]. 


\subsection{Percentage drug loading $(\% D L)\left(Y_{2}\right)$.}

The percentage drug loading of EFH-SLMs ranged from 13.31 to $19.99 \% \mathrm{w} / \mathrm{w}$. Model proposed quadratic polynomial equation for estimating the effect of selected variables on $\%$ DL $\left(Y_{2}\right)$. Synergistic effects $\mathrm{X}_{2}, \mathrm{X}_{3}$ and antagonistic effect of $X_{1}$ was observed for $\% \mathrm{DL}$ as illustrated by following equation:

$$
\begin{aligned}
& Y_{2}=17.55-1.77 X_{1}+0.093 X_{2}+0.408 X_{3}+0.3231 X_{1} X_{2}+0.0062 X_{1} X_{3}-0.2588 X_{2} X_{3}- \\
& 0.4056 X_{1}^{2}-0.2059 X_{2}^{2}-0.6213 X_{3}^{2}
\end{aligned}
$$

$\%$ DL was significantly influenced by $X_{1}, X_{3}, X_{1}^{2}, X_{2}^{2}$ and $X_{3}^{2}(p<0.05)$ (Table 3). Figure 2 depicted that increase in drug: lipid decreased drug loading may be attributable to the rise of lipid content and decline in EE. It depicted that enhancement in stirring speed primarily augmented the percent drug loading pursued by decline signifying that maximum drug loading can be accomplished at center level $[22,59]$.

Table 3. Analysis of variance for entrapment efficiency $\left(Y_{1}\right)$, drug loading $\left(Y_{2}\right)$, mean diameter $\left(Y_{3}\right)$, and process

\begin{tabular}{|c|c|c|c|c|c|c|c|c|}
\hline \multirow{2}{*}{$\begin{array}{l}\text { Model } \\
\text { term }\end{array}$} & \multicolumn{2}{|c|}{$Y_{1}$} & \multicolumn{2}{|c|}{$Y_{2}$} & \multicolumn{2}{|c|}{$Y_{3}$} & \multicolumn{2}{|c|}{$Y_{4}$} \\
\hline & $F$-value & $p$-value & $F$-value & $p$-value & $F$-value & $p$-value & $F$-value & $p$-value \\
\hline Model & 56.55 & $<0.0001 *$ & 24.94 & $<0.0001 *$ & 47.55 & $<0.0001 *$ & 52.16 & $<0.0001 *$ \\
\hline$b_{1}$ & 403.55 & $<0.0001 *$ & 177.99 & $<0.0001 *$ & 356.72 & $<0.0001 *$ & 347.86 & $<0.0001^{*}$ \\
\hline$b_{2}$ & 1.47 & 0.2528 & 0.4895 & 0.5001 & 2.28 & 0.1619 & 6.28 & $0.0311^{*}$ \\
\hline$b_{3}$ & 12.62 & $0.0053 *$ & 9.42 & $0.0119 *$ & 11.82 & $0.0063^{*}$ & 10.74 & $0.0083 *$ \\
\hline$b_{12}$ & 4.03 & 0.0724 & 3.42 & 0.0942 & 0.0019 & 0.9663 & 5.30 & $0.0441^{*}$ \\
\hline$b_{13}$ & 0.7307 & 0.4127 & 0.0013 & 0.9720 & 0.0081 & 0.9302 & 0.8475 & 0.3789 \\
\hline$b_{23}$ & 3.14 & 0.1068 & 2.22 & 0.1672 & 0.0520 & 0.8242 & 0.2956 & 0.5985 \\
\hline$b_{1}^{2}$ & 61.84 & $<0.0001 *$ & 9.82 & $0.0106^{*}$ & 6.18 & $0.0322 *$ & 79.40 & $<0.0001^{*}$ \\
\hline$b_{2}^{2}$ & 2.76 & 0.1276 & 2.53 & 0.1427 & 31.39 & $0.0002 *$ & 5.50 & $0.0409 *$ \\
\hline$b_{3}^{2}$ & 28.94 & $0.0003 *$ & 23.04 & $0.0007 *$ & 28.85 & $0.0003 *$ & 25.51 & $0.0005^{*}$ \\
\hline Lack of Fit & 1.68 & 0.2921 & 2.56 & 0.1625 & 3.87 & 0.0820 & 0.9148 & 0.5378 \\
\hline
\end{tabular}
yield $\left(Y_{4}\right)$ of eflornithine hydrochloride-loaded solid lipid microparticles.
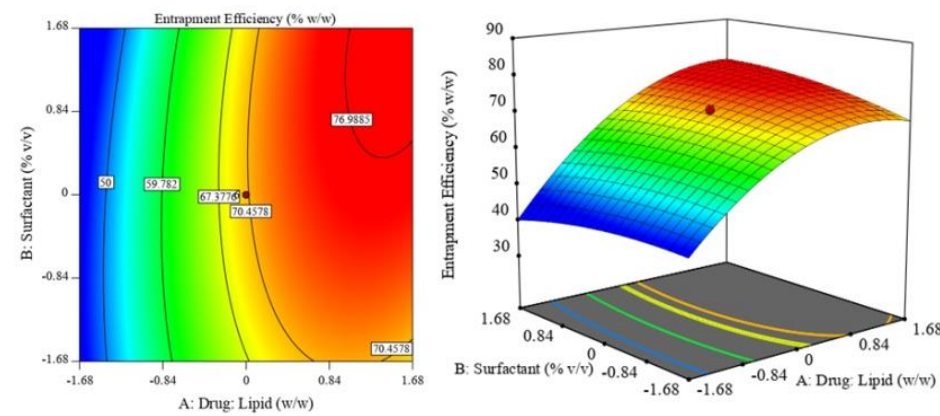

(a)
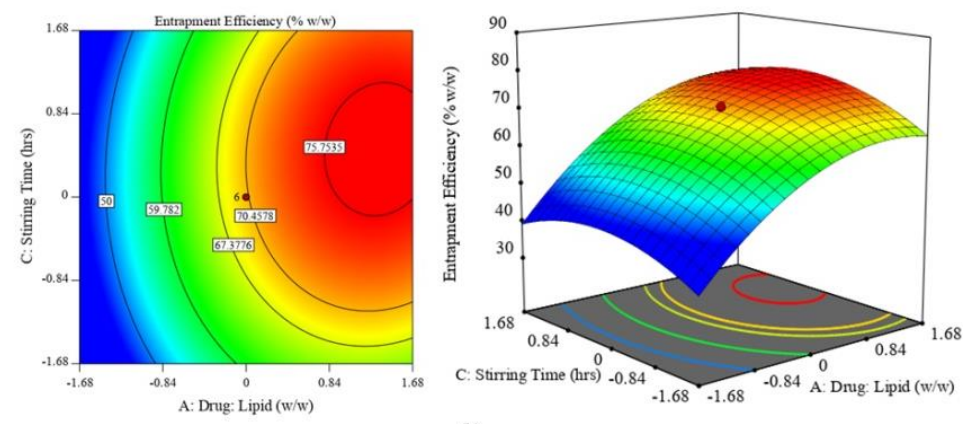

(b)

Figure 1. Response surface plots showing the effect of various factors on percentage entrapment efficiency. 

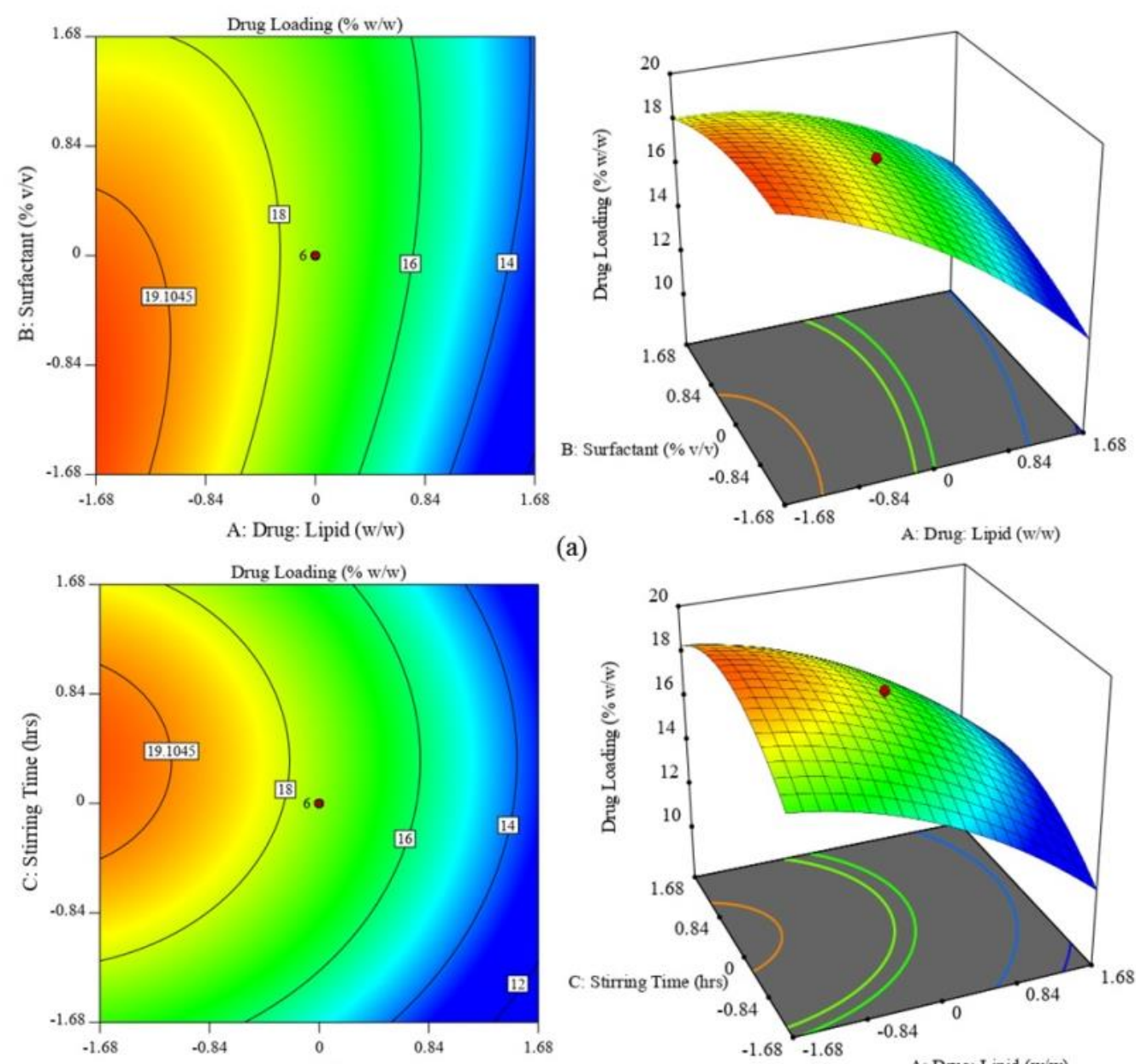

(a)
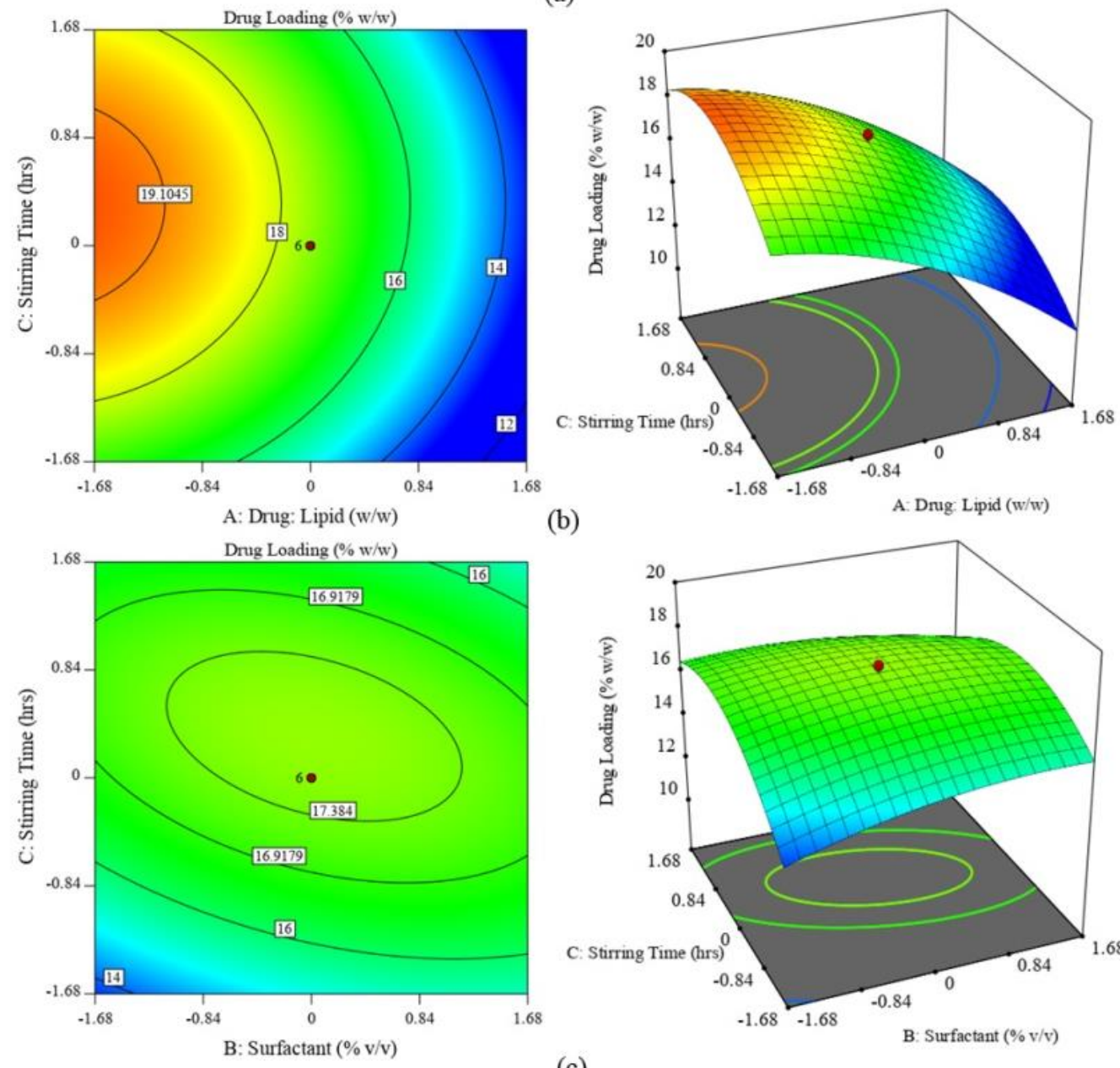

(b)

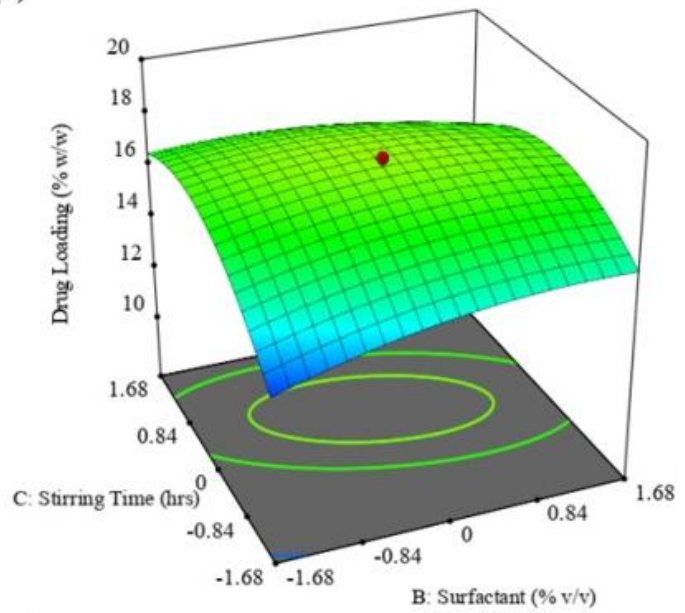

(c)

Figure 2. Response surface graphs demonstrating the effect of factors on percentage drug loading.

\subsection{Mean diameter $\left(Y_{3}\right)$.}

The mean diameter of EFH-SLMs varied from 58.75 to $155.42 \mu \mathrm{m}$. A second-order polynomial quadratic developed by multiple regression analysis of mean diameter values can satisfactorily illustrate the outcome of independent variables on mean diameter as indicated in the following equation.

$$
\begin{aligned}
Y_{3}=115.38 & +27.97 X_{1}-2.24 X_{2}-5.09 X_{3}+0.0837 X_{1} X_{2}-0.1738 X_{1} X_{3}-0.4413 X_{2} X_{3}-3.58 X_{1}^{2} \\
& -8.08 X_{2}^{2}-7.74 X_{3}^{2} \quad\left(r^{2}=0.9772\right)
\end{aligned}
$$


Model $F$-value $24.94(p<0.0001)$ and lack of fit $F$-value $2.56(p>0.05)$ suggested statistical significance of model. Surfactant concentration $\left(X_{2}\right)$ and stirring time $\left(X_{3}\right)$ had significant antagonistic while drug: lipid $\left(X_{1}\right)$ had a synergistic effect on the mean diameter of EFH-SLM. None of the significant interaction effects of variables was observed for mean diameter (Table 3). The effect of factors on the mean diameter of EFH-SLM has been displayed in Figure 3. The mean diameter of microparticles decreased significantly with an increase in stirring time (X3). The sheer force applied for a longer period might have produced smaller size microparticles. An increase in drug: lipid linearly increased the mean diameter of EFHSLM, which could be owing to an increase in viscosity of dispersion which provides enhanced resistance to sonication, therefore endorsing synthesis of larger microparticles [60, 61]. However, as indicated in equation $6, \mathrm{X}_{2}$ (surfactant concentration) showed a negative effect on mean diameter and through increasing $\mathrm{X}_{2}$, mean diameter decreased, which illustrated that the existence of higher surfactant concentration decreased interfacial tension efficiently, and lipids could be converted into highly homogenized droplets into an aqueous phase and circumvent coalescence leading to the production of smaller lipid microparticles [22, 58, 59, 62, 63].
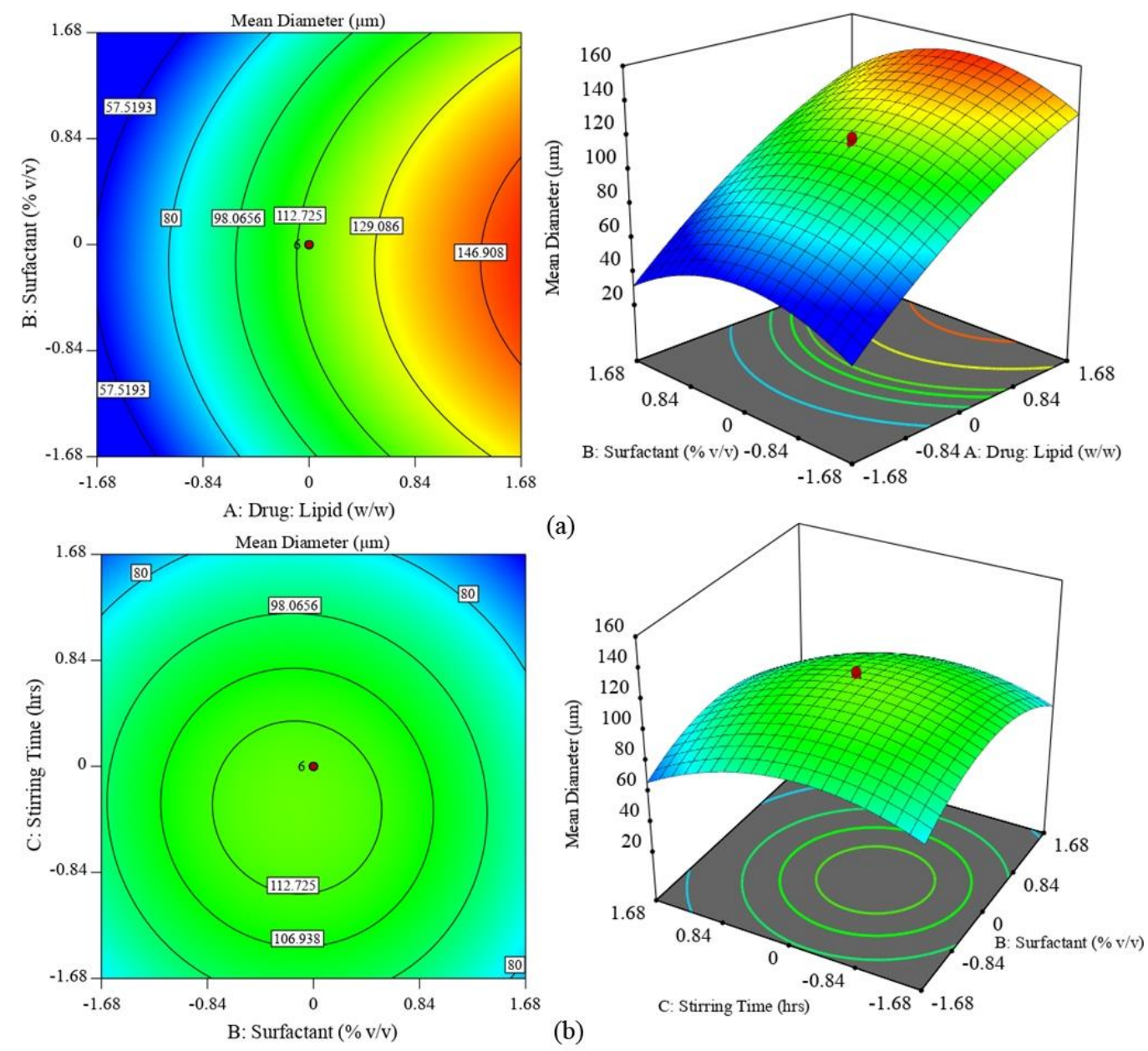

Figure 3. Response surface graphs displaying the effect of independent variables on mean diameter.

\subsection{Percentage process yield $\left(Y_{4}\right)$.}

The process yield of EFH-SLMs was found to range from 47.36 to $75.16 \%$ w/w. Independent variables significantly influencing the \% process yield of EFH-SLM were drug: lipid $\left(X_{1}\right)$, surfactant concentration $\left(X_{2}\right)$, and stirring time $\left(X_{3}\right)(p<0.05)$ (Table 3$)$. The effect can be elucidated through the mathematical relationship depicted in the following equation: 


$$
Y_{4}=72.8+9.09 X_{1}+1.22 X_{2}+1.6 X_{3}+1.47 X_{1} X_{2}+0.5863 X_{1} X_{3}-0.3462 X_{2} X_{3}-4.23 X_{1}{ }^{2}-
$$

$$
1.11 X_{2}^{2}-2.4 X_{3}^{2} \quad\left(r^{2}=0.9791\right)
$$

All the factors produced synergistic effects on the percentage process yield of EFHSLM as implied by a positive sign of coefficients. Figure 4 represented that increase in drug: lipid, surfactant concentration, and stirring time caused a positive impact on the $\%$ process yield of EFH-SLM. The process yield increased with a rise in the portion of lipid clearly due to higher lipid content, which accommodated more quantity of drug [35].
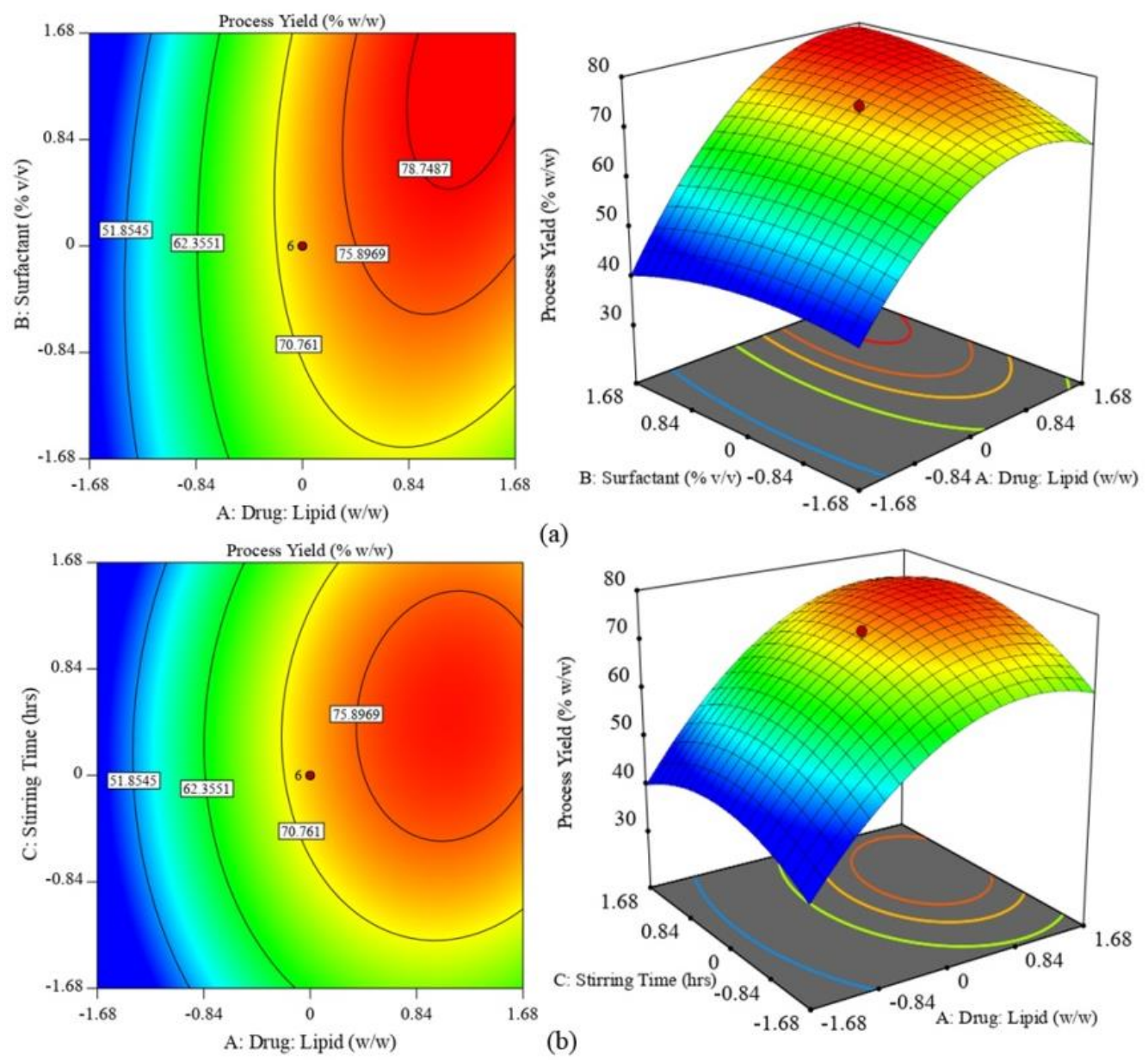

Figure 4. Response surface plots showing the effect of factors on percentage process yield.

\subsection{Optimized and validated EFH-SLM batch by numerical optimization method.}

Optimal values of formulation and process variables with the greatest overall desirability function $(D=0.806)$ were obtained through Design-Expert software. The composition of the software-suggested optimized EFH-SLM was 1:3.74 drug: lipid (w/w) $\left(X_{1}\right)$, $1.84 \%$ surfactant concentration $\left(X_{2}\right)$, and $3.5 \mathrm{~h}$ stirring time $\left(X_{3}\right)$. Figure 5 shows the response surface plot and the corresponding counter-plot for the overall desirability coefficient for optimized EFH-SLM. The experimental values of $Y_{1}, Y_{2}, Y_{3}$, and $Y_{4}$ were $73.21 \%, 15.3 \%$, $100.7 \mu \mathrm{m}$, and $76.84 \%$, while corresponding predicted values were $74.97 \% 15.84 \%, 102.8 \mu \mathrm{m}$, and $78.07 \%$. The percentage error between experimental and predicted Y1, Y2, Y3, and Y4 values was $2.34,3.4,2.04$, and 1.57 , respectively [64]. 

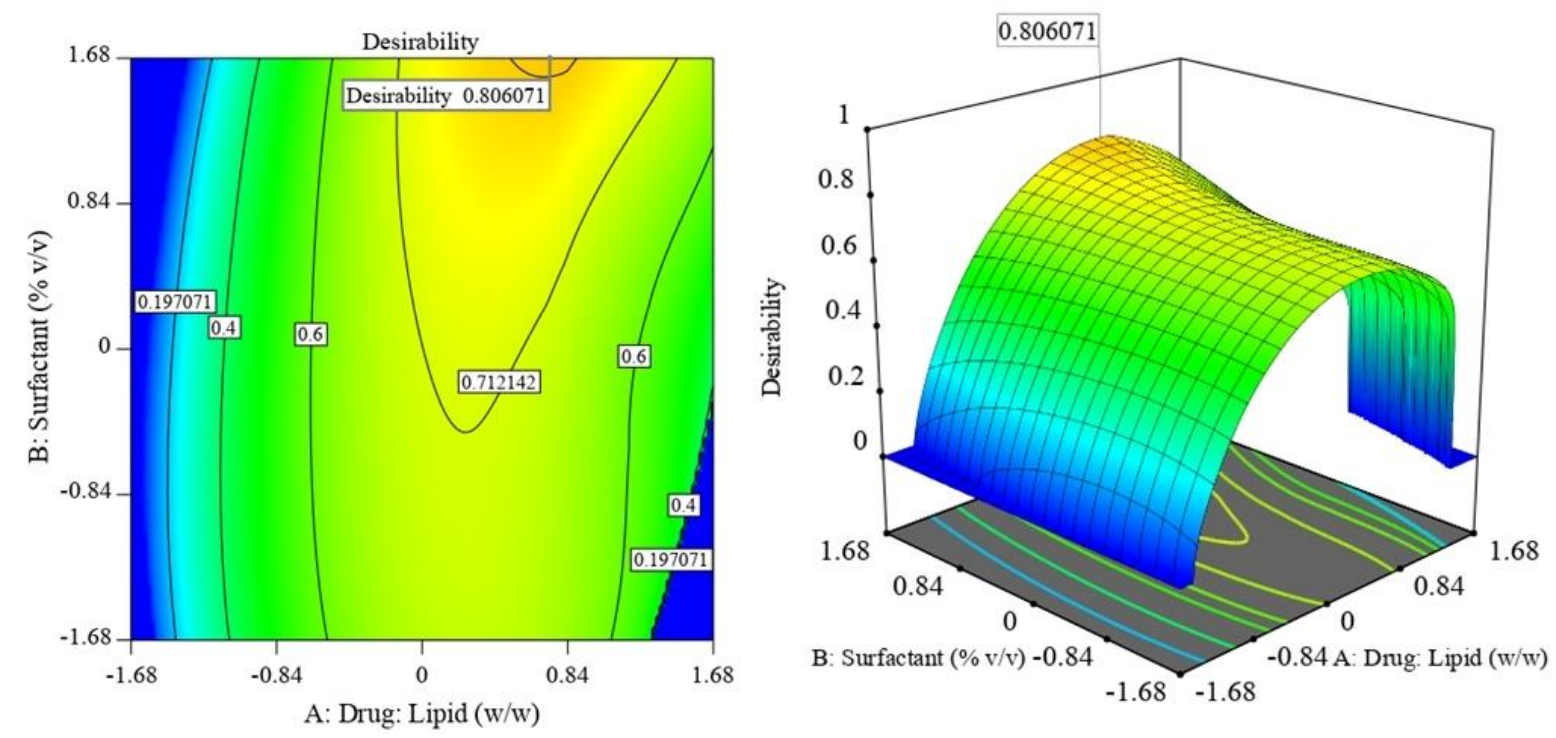

Figure 5. Response surface (3D) and corresponding counter (2D) plots for desirability function of optimized eflornithine hydrochloride-loaded solid lipid microparticles.

\subsection{Evaluation of optimized EFH-SLM.}

\subsubsection{X-ray diffraction.}

XRD pattern of EFH demonstrated distinctive peaks at $5.1^{\circ}, 10.4^{\circ}, 11.5^{\circ}, 19.7^{\circ}, 22.3^{\circ}$, $24.2^{\circ}, 25.4^{\circ}, 26.1^{\circ}, 31.3^{\circ}, 32.4^{\circ}$ and $41.1^{\circ}$ at $2 \theta$ scale, which confirmed the crystalline feature of a drug (Figure 6a). Monecol PC illustrated a single peak at $24.65^{\circ}$ (Figure 6b). Softemul 165 showed few peaks at $3.45^{\circ}, 19.6^{\circ}$, and $24.7^{\circ}$ (Figure $6 \mathrm{c}$ ). , The physical mixture's x-ray diffractogram revealed peaks of a drug as well as lipids which confirmed their compatibility (Figure 6d). There was a deficiency of prominent sharp patterns in EFH-SLM, which supported the conversion of drugs into an amorphous state (Figure 6e) [21, 65-68].

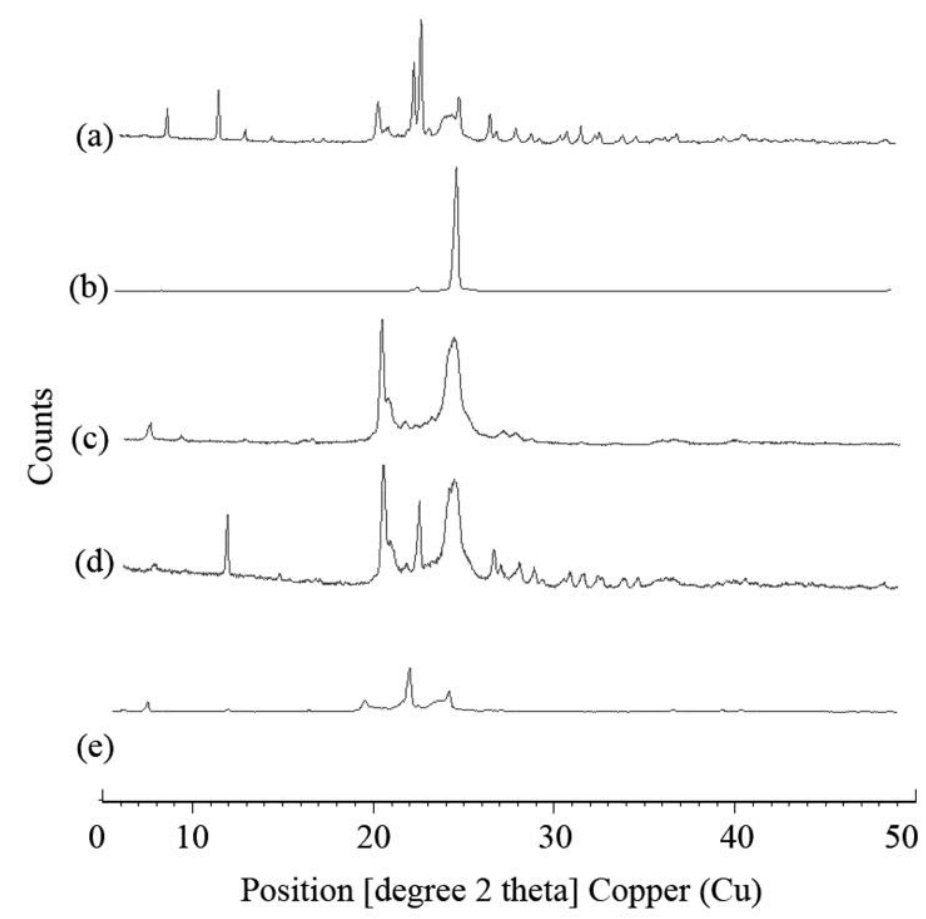

Figure 6. XRD patterns of (a) eflornithine hydrochloride (b) Monecol PC (c) Softemul 165 (d) physical mixture of eflornithine hydrochloride, Monecol PC and Softemul 165, and (e) eflornithine hydrochloride-loaded solid lipid microparticles. 


\subsubsection{Dynamic light scattering (DLS).}

DLS was executed to illustrate the mean diameter (z-average) along with polydispersity index (PDI) of optimized EFH-SLM for particle size distribution analysis. Z-average and PDI of EFH-SLM were $1.38 \pm 0.59 \mu \mathrm{m}$ and 0.188 , correspondingly which showed a high degree of homogeneity and comparatively narrow particle size distribution (Figure 7). The smaller diameter of EFH-SLM could be attributable to tween 20, which decreases surface tension over lipid particle interfaces and produce uniform particle size distribution [21, 65, 68].

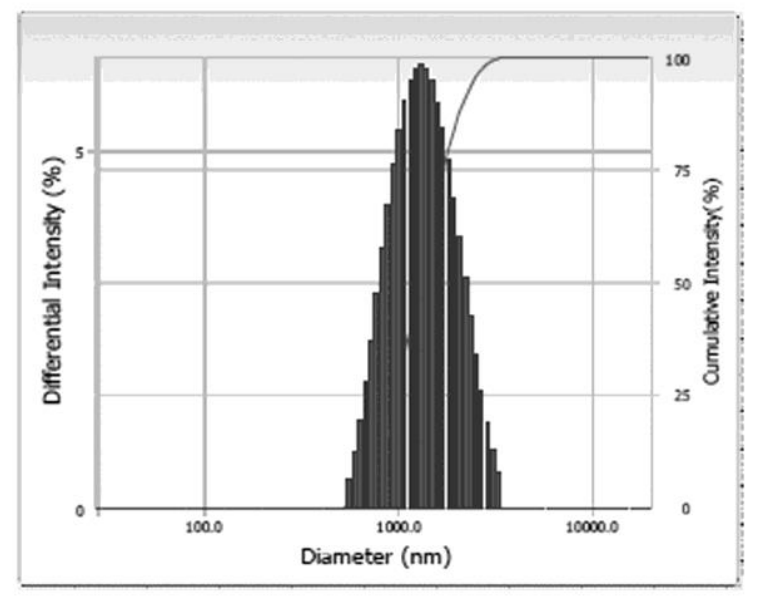

Figure 7. Intensity distributions analysis of eflornithine hydrochloride-loaded solid lipid microparticles.

\subsubsection{Scanning electron microscopy analysis.}

SEM expressed the morphological texture of EFH-SLM and illustrated spherical shape and smooth exterior morphology of SLM (Figure 8) [51, 58, 66, 69].
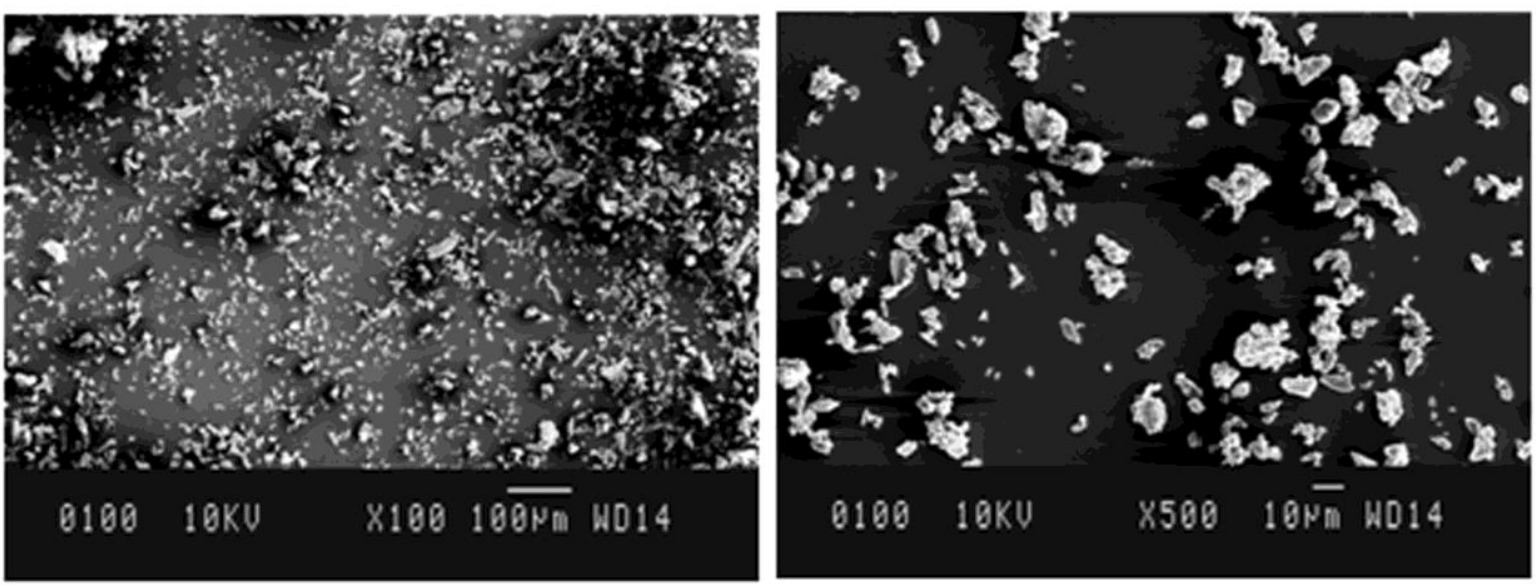

Figure 8. Scanning electron micrographs of optimized eflornithine hydrochloride-loaded solid lipid microparticles.

\subsection{Evaluation of optimized EFH-SLM loaded topical cream (EFH-SLM-C).}

\subsubsection{Physical appearance, Spreadability, $\mathrm{pH}$ value, and viscosity.}

The creams appeared aesthetically acceptable, pleasant to feel, non-gritty, and homogenous in texture without any signs of phase separation. The spreadability time was $14 \pm 2$ seconds with merely small shear stress. The $\mathrm{pH}$ of the EFH-SLM-C was found $6.3 \pm 0.2$, which ensures that it could be indicated to treat Hirsutism with a lower risk of skin irritation since 
topical dosage form should have a $\mathrm{pH}$ range of 6-7 to prevent skin $\mathrm{pH}$ alteration [18-20]. The viscosity of EFH-SLM-C was found 12500, 8100, 4600, and $3100 \mathrm{cP}$ at 10, 20, 50, and 100 rpm shear rate, respectively (Figure 9). The creams' viscosity diminishes as the shear rate increases, which could be attributable to the disentanglement and unidirectional alignment of cream's molecules under the shear's influence. Such flow pattern has been recognized as pseudo-plasticity or shear-thinning, which tends to make cream convenient to spread over the skin $[46-50,70]$.

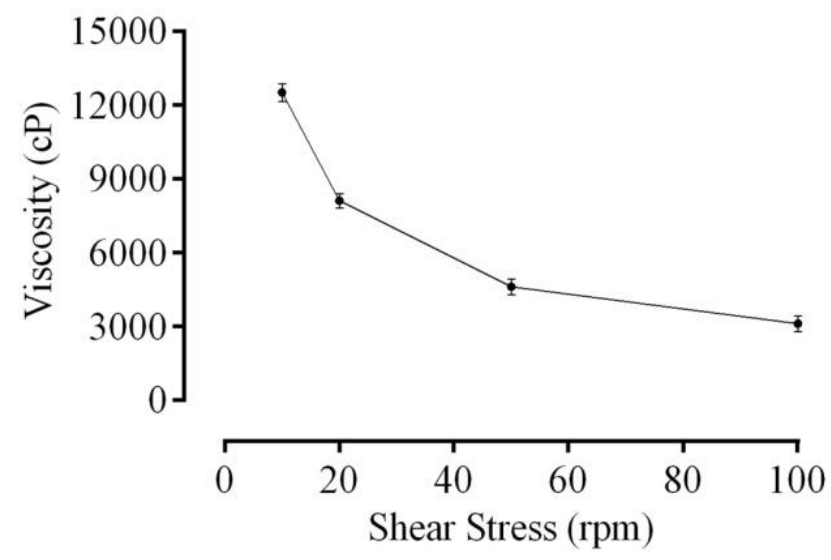

Figure 9. Viscosity curves for the eflornithine hydrochloride solid lipid microparticles loaded cream ( $n=3$, results shown as mean $\pm \mathrm{SD}$ ).

\subsubsection{Thermodynamic stability.}

No phase separation was visible after thermodynamic stability study via heatingcooling cycle and centrifugation test, which illustrated topical EFH-SLM-C [47] stability.

\subsubsection{Percentage drug content.}

The drug content in EFH-SLM-C was found 98.42\%, which indicated that EFH was uniformly distributed in the cream dosage form, and the loss of drug during formulation processes was insignificant [46].

\subsubsection{In-vitro drug release study.}

In-vitro drug release from the EFH-C, EFH-PM-C, and EFH-SLM-C was performed in phosphate buffer, pH 6.8 using Franz diffusion cell over $24 \mathrm{~h}$. In the first $12 \mathrm{~h}$, approximately $45.58 \%$ and $45.98 \%$ drug was released from EFH-C and EFH-PM-C, respectively, whereas EFH-SLM-C revealed a biphasic fickian diffusion release pattern with an initial 'burst release' of approximately $16.95 \%$ loosely bound $\mathrm{EFH}$ on or near the surface of lipid particles during first $0.5 \mathrm{~h}$ succeeded by the release of $52.31 \%$ drug within $4 \mathrm{~h}$. Afterward, sustained release of the drug due to diffusion from lipid matrix with maximum drug release of $88.75 \%$ over $24 \mathrm{~h}$ was achieved (Figure 10). EFH-SLM-C release profile report suggests that SLMs were able to release EFH in a sustained fashion as cumulative drug release over $24 \mathrm{~h}$ was between 16.95 and 88.75 percent. This sustained drug release from SLMs indicates relatively homogenous dispersal of the drug into the lipid matrix [52-54, 71-74]. 


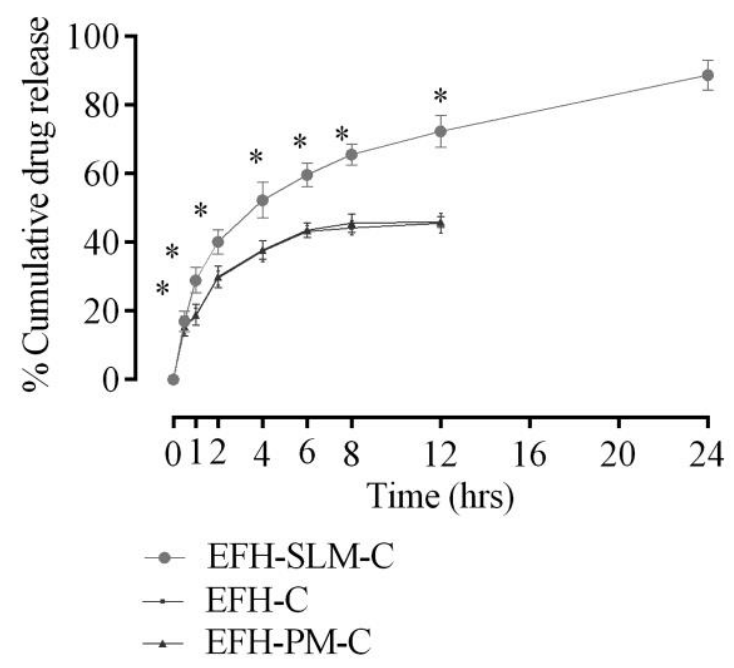

Figure 10. In-vitro drug release pattern from creams incorporating eflornithine hydrochloride (EFH-C), physical mixture of drug and lipids (EFH-PM-C), and eflornithine hydrochloride solid lipid microparticles (EFH-SLM-

C).

\subsubsection{Permeation data analysis.}

The cumulative amounts of EFH permeated per unit area from creams incorporating EFH-C, EFH-PM-C and EFH-SLM-C are revealed in Figure 11. This was observed that the quantities of EFH permeated across the membrane by EFH-SLM-C were considerably higher $(* p<0.05)$ compared to EFH-C and EFH-PM-C. The in-vitro steady-state flux $\left(J_{\mathrm{ss}}\right)\left(\mu \mathrm{gcm}^{-2} \mathrm{~h}^{-}\right.$ 1) through the artificial membrane from EFH-C, EFH-PM-C, and EFH-SLM-C were 17.27, 17.41 , and 36.65 while apparent permeability coefficient $\left(P_{\text {app }}\right)\left(\mathrm{cmh}^{-1}\right)$ were $0.046,0.0464$ and 0.0977 , respectively. These statistics revealed significant differences in flux and $P$ app of EFHSLM-C and EFH-C $\left({ }^{*} p<0.05\right)[12,49,53,55]$. The significantly enhanced permeation of EFH from EFH-SLM-C over EFH-C is accredited to the existence of drugs and surfactants at a micro-scale, which synergistically improves the permeation of EFH $[66,71,75]$.

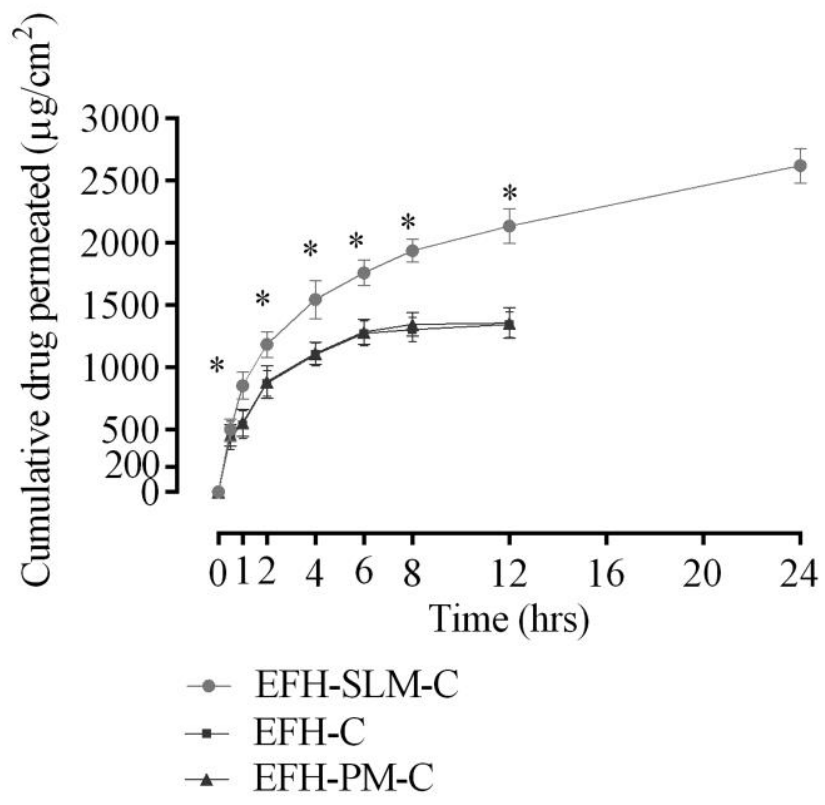

Figure 11. Comparative drug permeation profile from cream incorporating eflornithine hydrochloride (EFH-C), physical mixture of drug and lipids (EFH-PM-C), and eflornithine hydrochloride solid lipid microparticles (EFH-SLM-C). 


\subsubsection{Release kinetics.}

Zero-order, first-order, Higuchi, and Korsmeyer-Peppas have been applied to describe the drug release mechanism from EFH-SLM-C. The correlation coefficients for zero-order, first-order, Higuchi and Korsmeyer-Peppas models were found to be 0.8, 0.6001, 0.9479, and 0.9626 , respectively (Figure 12). The release exponent ' $n$ ' for the Korsmeyer-Peppas model was found to be $0.411(n<0.45)$, indicating that fickian diffusion conquered the drug release mechanism from EFH-SLM-C [56, 66].

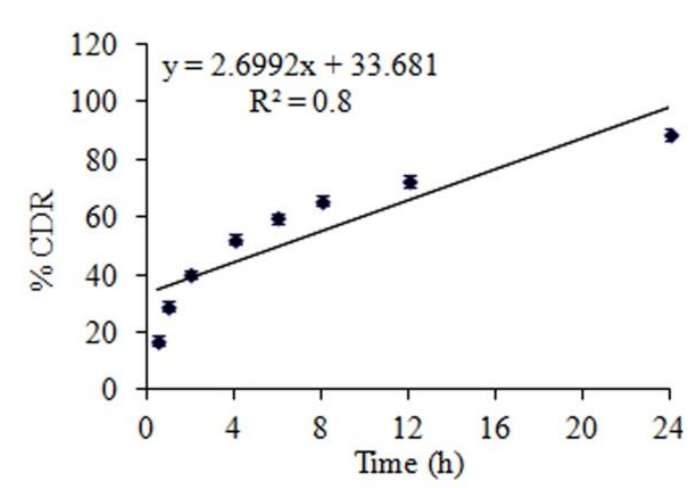

(a) Zero Order

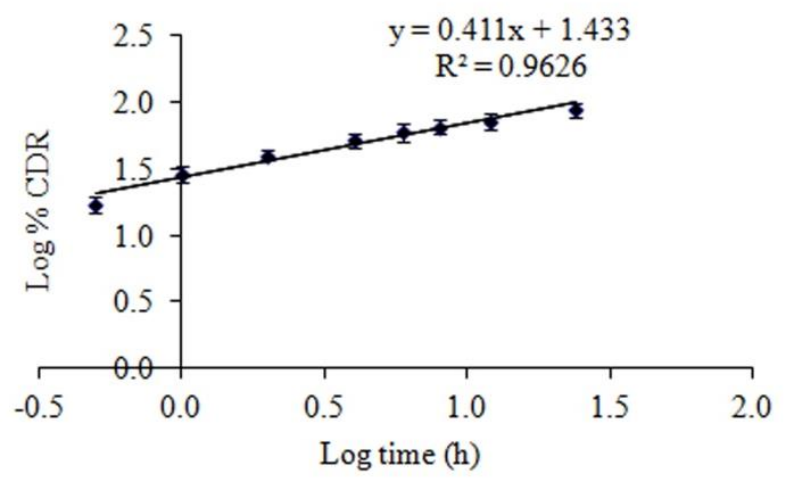

(c) Korsmeyer Peppas

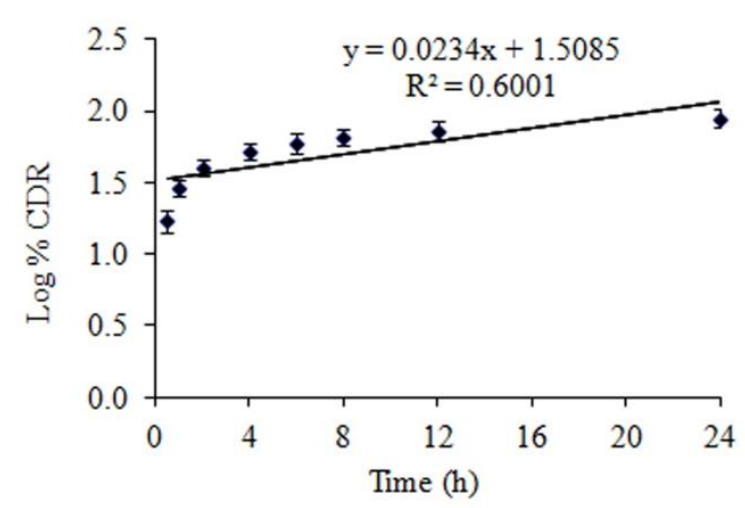

(b) First Order

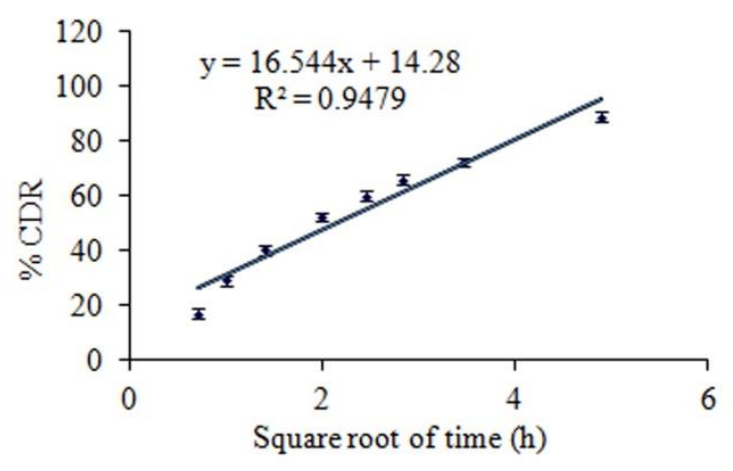

(d) Higuchi

Figure 12. In-vitro drug release kinetic model from eflornithine hydrochloride solid lipid microparticles loaded cream (a) zero-order, (b) first-order, (c) Korsmeyer-Peppas, and (d) Higuchi.

\section{Conclusions}

Hirsutism is the presence of excess terminal hairs, which makes it a highly distressing disease. Topical application of EFH is the only available non-hormonal and non-systemic choice available for hirsutism treatment to combat the drawbacks of existing therapies. The EFH-SLM composed of Monecol PC and Softemul 165 were successfully developed using emulsion solvent evaporation technique with enhanced permeation and minimization of dose, frequency of application, and reduced local adverse effects such as irritation, acne, skin itching, stinging, burning, and rashes. The central composite design has been applied to inspect the influence of formulation and processing variables on response parameters. Design expert software illustrated that an optimized EFH-SLM having desirability function (0.806) could be achieved using 1:3.74 drug: lipid (w/w) $\left(X_{1}\right), 1.84 \%$ surfactant concentration $\left(X_{2}\right)$, and $3.5 \mathrm{~h}$ stirring time $\left(X_{3}\right)$, which would illustrate entrapment efficiency $(74.97 \%)$, drug loading $(15.84 \%)$, mean diameter $(102.8 \mu \mathrm{m})$ and process yield $(78.07 \%)$. X-ray diffraction and 
scanning electron microscopy confirmed the amorphous nature and spherical shape of optimized EFH-SLM. The polydispersity index of EFH-SLM using dynamic light scattering was found 0.188 , which showed a high degree of homogeneity in particle size distribution. EFH-SLM-C revealed biphasic fickian diffusional release of $16.95 \%$ within $0.5 \mathrm{~h}, 52.31 \%$ in the next $4 \mathrm{~h}$ followed by sustained release of $88.75 \%$ over $24 \mathrm{~h}$. This was confirmed by release exponent $0.411(n<0.45)$ for Korsmeyer-Peppas. In-vitro steady-state flux $\left(J_{\mathrm{ss}}\right)\left(\mu \mathrm{gcm}^{-2} \mathrm{~h}^{-1}\right)$ from EFH-C and EFH-SLM-C were 17.27 and 36.65 while apparent permeability coefficient $\left(P_{\text {app }}\right)\left(\mathrm{cmh}^{-1}\right)$ was 0.046 and 0.0977 , respectively. It has been concluded that EFH-SLM-C could be a promising strategy for augmented permeation with minimization of dose, frequency of application, and local adverse effects.

\section{Funding}

This research received no external funding.

\section{Acknowledgments}

The authors express gratitude to Chitkara College of Pharmacy, Chitkara University, Punjab, India, for motivational support for this review's compilation.

\section{Conflicts of Interest}

The authors declare no conflict of interest.

\section{References}

1. Matheson, E.; Bain, J. Hirsutism in women. Am. Fam. Physician. 2019, 100, 168-175.

2. Watts, J. Understanding the causes and management of Hirsutism. Nurs. Times. 2006, 102, 26-28.

3. Soran Sameei, H.S.; Ghasemnejad-Berenji, M. A novel effect of acyclovir on hair growth in BALB/c mice: A promising future for finding a new topical drug for the treatment of Hirsutism. Clin. Cosmet. Investig. Dermatol. 2020, 13, 319-324, https://doi.org/10.2147/CCID.S243388

4. Karakurt, F.; Sahin, I.; Güler, S.; Demirbas, B.; Culha, C.; Serter, R.; Aral, Y.; Bavbek, N. Comparison of the clinical efficacy of flutamide and spironolactone plus ethinyloestradiol/cyproterone acetate in the treatment of Hirsutism: a randomised controlled study. Adv Ther. 2008, 25, 321-328, https://doi.org/10.1007/s12325-008-0039-5.

5. Swiglo, B.A.; Cosma, M.; Flynn, D.N.; Kurtz, D.M.; Labella, M.L.; Mullan, R.J.; Erwin, P.J.; Montori, V.M. Clinical review: Antiandrogens for the treatment of Hirsutism: a systematic review and metaanalyses of randomized controlled trials. J. Clin. Endocrinol. Metab. 2008, 93, 1153-1160, https://doi.org/10.1210/jc.2007-2430.

6. Załęska, I.; Atta-Motte, M.; Aspects of diode laser $(805 \mathrm{~nm})$ hair removal safety in a mixed-race group of patients. J. Lasers Med. Sci. 2019, 10, https://dx.doi.org/10.15171/jlms.2019.23.

7. Agrawal, N.K. Management of Hirsutism. Indian J. Endocrino. Metab. 2013, 17, 77-82, https://dx.doi.org/10.4103\%2F2230-8210.119511.

8. Maia, C.S.; Mehnert, W.; Schaller, M.; Korting, H.C.; Gysler, A.; Haberland, A.; Schäfer-Korting, M. Drug targeting by solid lipid nanoparticles for dermal use. J. Drug Target. 2002, 10, 489-495, https://doi.org/10.1080/1061186021000038364.

9. Naik, A.; Kalia, Y.N.; Guy, R.H.; Fessi, H. Enhancement of topical delivery from biodegradable nanoparticles. Pharm. Res. 2004, 21, 1818-1825, https://doi.org/10.1023/B:PHAM.0000045235.86197.ef.

10. Gaba, B.; Fazil, M.; Khan, S.; Ali, A; Baboota, S.; Ali, J. Nanostructured lipid carrier system for topical delivery of terbinafine hydrochloride. Bull. Fac. Pharm. (Cairo Univ). 2015, 53, 147-159, https://doi.org/10.1016/j.bfopcu.2015.10.001.

11. Cevc, G. Lipid vesicles and other colloids as drug carriers on the skin. Adv. Drug Deliv. Rev. 2004, 56, 675711, https://doi.org/10.1016/j.addr.2003.10.028.

12. Vaz, S.; Silva, R.; Amaral, M.H.; Martins, E.; Lobo, J.S.; Silva, A.C. Evaluation of the biocompatibility and skin hydration potential of vitamin E-loaded lipid nanosystems formulations: In vitro and human in vivo studies. Colloids Surf. B. 2019, 179, 242-249, https://doi.org/10.1016/j.colsurfb.2019.03.036. 
13. Souto, E.B.; Baldim, I.; Oliveira, W.P.; Rao, R.; Yadav, N.; Gama, F.M.; Mahant, S. SLN and NLC for topical, dermal, and transdermal drug delivery. Expert Opin Drug Deliv. 2020, 17, 357-377, https://doi.org/10.1080/17425247.2020.1727883.

14. Muller, R.H.; Radtke, M.; Wissing, S.A. Solid lipid nanoparticles (SLN) and nanostructured lipid carriers (NLC) in cosmetic and dermatological preparations. Adv. Drug Deliv. Rev. 2002, 54, 131-155, https://doi.org/10.1016/S0169-409X(02)00118-7.

15. Muller, R.H.; Petersen, R.D.; Hommoss, A.; Pardeike, J. Nanostructured lipid carriers (NLC) in cosmetic dermal products. Adv. Drug Deliv. Rev. 2007, 59, 522-530, https://doi.org/10.1016/j.addr.2007.04.012.

16. Schäfer-Korting, M.; Mehnert, W.; Korting, H.C. Lipid nanoparticles for improved topical application of drugs for skin diseases. Adv. Drug Deliv. Rev. 2007, 59, 427-443,https://doi.org/10.1016/j.addr.2007.04.006.

17. Shah, K.A.; Date, A.A.; Joshi, M.D.; Patravale, V.B. Solid lipid nanoparticles (SLN) of tretinoin: potential in topical delivery. Int. J. Pharm. 2007, 345, 163-171, https://doi.org/10.1016/j.ijpharm.2007.05.061.

18. Angelo, T.; El-Sayed, N.; Jurisic, M.; Koenneke, A.; Gelfuso, G.M.; Cunha-Filho, M.; Taveira, S.F.; Lemor, R.; Schneider, M.; Gratieri, T. Effect of physical stimuli on hair follicle deposition of clobetasol loaded lipid nanocarriers. Sci. Rep. 2020, 10, 176-189, https://doi.org/10.1038/s41598-019-56760-w.

19. Shah, M.; Agrawal, Y. Ciprofloxacin hydrochloride-loaded glyceryl monostearate nanoparticle: factorial design of Lutrol F68 and Phospholipon 90G. J. Microencapsul. 2012, 29, 331-343, https://doi.org/10.3109/02652048.2011.651498.

20. Shamma, R.N.; Aburahma, M.H. Follicular delivery of spironolactone via nanostructured lipid carriers for management of alopecia. Int. J. Nanomedicine. 2014, 9, 5449-5460, https://dx.doi.org/10.2147\%2FIJN.S73010.

21. Velmurugan, R.; Selvamuthukumar, S. Development and optimization of ifosfamide nanostructured lipid carriers for oral delivery using response surface methodology. Appl. Nanosci. 2016, 6, 159-173, https://doi.org/10.1007/s13204-015-0434-6.

22. Das, S.; Ng, W.K.; Kanaujia, P.; Kim, S.; Tan, R.B. Formulation design, preparation and physicochemical characterizations of solid lipid nanoparticles containing a hydrophobic drug: effects of process variables. Colloids Surf. B. 2011, 88, 483-489, https://doi.org/10.1016/j.colsurfb.2011.07.036.

23. Capretto, L.; Mazzitelli, S.; Nastruzzi, C. Design, production and optimization of solid lipid microparticles (SLM) by a coaxial microfluidic device J. Control. Release. 2012, 160, 409-417, https://doi.org/10.1016/j.jconrel.2012.04.019.

24. Agarwal, S.; Murthy, R.S.; Harikumar, S.L.; Garg, R. Quality by design approach for development and characterisation of solid lipid nanoparticles of quetiapine fumarate. Curr. Comput. Aided Drug Des. 2020, 16, 73-91, https://doi.org/10.2174/1573409915666190722122827.

25. Pinto, F.; de Barros, D.P.; Reis, C.; Fonseca, L.P. Optimization of nanostructured lipid carriers loaded with retinoids by central composite design. J. Mol. Liq. 2019, 293, https://doi.org/10.1016/j.molliq.2019.111468.

26. Hu, F.Q.; Yuan, H.; Zhang, H.H.; Fang, M. Preparation of solid lipid nanoparticles with clobetasol propionate by a novel solvent diffusion method in aqueous system and physicochemical characterization. Int. J. Pharm. 2002, 239, 121-128, https://doi.org/10.1016/S0378-5173(02)00081-9.

27. Hu, F.Q.; Zhang, Y.; Du, Y.Z.; Yuan, H. Nimodipine loaded lipid nanospheres prepared by solvent diffusion method in a drug saturated aqueous system. Int. J. Pharm. 2008, 348, 146-152, https://doi.org/10.1016/j.ijpharm.2007.07.025.

28. Mehnert, W.; Mader, K. Solid lipid nanoparticles: production, characterization and applications. Adv. Drug Deliv. Rev. 2001, 47, 165-196, https://doi.org/10.1016/j.addr.2012.09.021.

29. Patil, S.B.; Sawant, K.K. Development, optimization and in vitro evaluation of alginate mucoadhesive microspheres of carvedilol for nasal delivery. J. Microencapsul. 2009, 26, 432-443, https://doi.org/10.1080/02652040802456726.

30. Trotta , M.; Debernardi, F.; Caputo, O. Preparation of solid lipid nanoparticles by a solvent emulsificationdiffusion technique. Int. J. Pharm. 2003, 257, 153-160, https://doi.org/10.1016/S0378-5173(03)00135-2.

31. Rajinikanth, P.S.; Chellian, J. Development and evaluation of nanostructured lipid carrier-based hydrogel for topical delivery of 5-fluorouracil. Int. J. Nanomedicine. 2016, 11, 5067-5077, https://dx.doi.org/10.2147\%2FIJN.S117511.

32. Silva, A.C.; Santos, D.; Ferreira, D.C.; Souto, E.B. Minoxidil-loaded nanostructured lipid carriers (NLC): characterization and rheological behaviour of topical formulations. Pharmazie. 2009, 64, 177-182, https://doi.org/10.1691/ph.2009.8232.

33. Souto, E.B.; Wissing, S.A.; Barbosa, C.M.; Muller, R.H. Development of a controlled release formulation based on SLN and NLC for topical clotrimazole delivery. Int. J. Pharm. 2004, 271, 71-77, https://doi.org/10.1016/j.ijpharm.2004.02.032.

34. Kemala, T.; Budianto, E.; Soegiyono, B. Preparation and characterization of microspheres based on blend of poly(lactic acid) and poly(e-caprolactone) with poly(vinyl alcohol) as emulsifier. Arab. J. Chem. 2012, 5, 103-108, https://doi.org/10.1016/j.arabjc.2010.08.003.

35. Gaur, P.K.; Mishra, S.; Bajpai, M. Formulation and evaluation of controlled-release of telmisartan microspheres: In vitro/in vivo study. J. Food Drug Anal. 2014, 22, 542-548, https://doi.org/10.1016/j.jfda.2014.05.001. 
36. Ali, H.; Singh, S.K. Preparation and characterization of solid lipid nanoparticles of furosemide using quality by design. Particul. Sci. Technol. 2018, 36, 695-709, https://doi.org/10.1080/02726351.2017.1295293.

37. Mahmoud, R.A.; Hussein, A.K.; Nasef, G.A.; Mansour, H.F. Oxiconazole nitrate solid lipid nanoparticles: formulation, in-vitro characterization and clinical assessment of an analogous loaded carbopol gel. Drug Dev Ind Pharm. 2020, 46, 706-716, https://doi.org/10.1080/03639045.2020.1752707.

38. Farboud, E.S.; Nasrollahi, S.A.; Tabbakhi, Z. Novel formulation and evaluation of a Q10-loaded solid lipid nanoparticle cream: in vitro and in vivo studies. Int. J. Nanomedicine. 2011, 6, 611-617, https://dx.doi.org/10.2147\%2FIJN.S16815.

39. Gad, H.A.; Abd El-Rahman, F.A.; Hamdy, G.M. Chamomile oil loaded solid lipid nanoparticles: A naturally formulated remedy to enhance the wound healing. J. Drug Deliv. Sci. Technol. 2019, 50, 329-338, https://doi.org/10.1016/j.jddst.2019.01.008.

40. Kim, M.H.; Jeon, Y.E.; Kang, S.; Lee, J.Y.; Lee, K.W.; Kim, K.T.; Kim, D.D. Lipid nanoparticles for enhancing the physicochemical stability and topical skin delivery of orobol. Pharmaceutics 2020, 12, https://doi.org/10.3390/pharmaceutics12090845.

41. Guo, C.; Yang, C.; Li, Q.; Tan, Q.; Liu, W.; Zhai, G. Development of a quercetin-loaded nanostructured lipid carrier formulation for topical delivery. Int. J. Pharm. 2012, 430, 292-298, https://doi.org/10.1016/j.ijpharm.2012.03.042.

42. Patel, D.; Dasgupta, S.; Dey, S.; Ramani, Y.R.; Ray, S.; Mazumder, B. Nanostructured lipid carriers (NLC)based gel for the topical delivery of aceclofenac: preparation, characterization, and in vivo evaluation. Sci. Pharm. 2012, 80, 749-764, https://doi.org/10.3797/scipharm.1202-12.

43. Mishra, A.P.; Saklani, S.; Milella, L.; Tiwari, P. Formulation and evaluation of herbal antioxidant face cream of Nardostachys jatamansi collected from Indian Himalayan region. Asian Pac. J. Trop. Biomed. 2014, 4, 679-682, https://doi.org/10.12980/APJTB.4.2014APJTB-2014-0223.

44. Tou, K.A.; Rehman, K.; Ishak, W.M.; Zulfakar, M.H. Influence of omega fatty acids on skin permeation of a coenzyme Q10 nanoemulsion cream formulation: characterization, in silico and ex vivo determination. Drug Dev Ind Pharm. 2019, 45, 1451-1458, https://doi.org/10.1080/03639045.2019.1628042.

45. Mohammed Haneefa, K.P.; Shahima Hanan, K.; Saraswathi, R.; Mohanta, G.P.; Nayar, C. Formulation and evaluation of herbal gel of Pothos scandens Linn. Asian Pac. J. Trop. Med. 2010, 3, 988-992, https://doi.org/10.1016/S1995-7645(11)60015-1.

46. Abdulbaqi, I.M.; Darwis, Y.; Assi, R.A.; Khan, N.A.K. Transethosomal gels as carriers for the transdermal delivery of colchicine: statistical optimization, characterization, and ex vivo evaluation. Drug Des. Devel. Ther. 2018, 12, 795-813, https://dx.doi.org/10.2147\%2FDDDT.S158018.

47. Hashem, F.M.; Shaker, D.S.; Ghorab, M.K.; Nasr, M.; Ismail, A. Formulation, characterization, and clinical evaluation of microemulsion containing clotrimazole for topical delivery. AAPS PharmSciTech. 2011, 12, 879-886, https://doi.org/10.1208/s12249-011-9653-7.

48. Tatke, A.; Dudhipala, N.; Janga, K.Y.; Balguri, S.P.; Avula, B.; Jablonski, M.M.; Majumdar, S. In situ gel of triamcinolone acetonide-loaded solid lipid nanoparticles for improved topical ocular delivery: Tear kinetics and ocular disposition studies. Nanomaterials 2019, 9, https://doi.org/10.3390/nano9010033.

49. El-Housiny, S.; Eldeen, M.A.S.; El-Attar, Y.A.; Salem, H.A.; Attia, D.; Bendas, E.R.; El-Nabarawi, M.A. Fluconazole-loaded solid lipid nanoparticles topical gel for treatment of pityriasis versicolor: formulation and clinical study. Drug Deliv. 2018, 25, 78-90, https://doi.org/10.1080/10717544.2017.1413444.

50. Amasya, G.; Inal, O.; Sengel-Turk, C.T. SLN enriched hydrogels for dermal application: Full factorial design study to estimate the relationship between composition and mechanical properties. Chem. Phys. Lipids 2020, 228, https://doi.org/10.1016/j.chemphyslip.2020.104889.

51. Sanna, V.; Gavini, E.; Cossu, M.; Rassu, G.; Giunchedi, P. Solid lipid nanoparticles (SLN) as carriers for the topical delivery of econazole nitrate: in-vitro characterization, ex-vivo and in-vivo studies. J. Pharm. Pharmacol. 2007, 59, 1057-1064, https://doi.org/10.1211/jpp.59.8.0002.

52. Kesharwani, R.; Sachan, A.; Singh, S.; Patel, D. Formulation and evaluation of solid lipid nanoparticle (SLN) based topical gel of etoricoxib. J. Appl. Pharm. 2016, 6, 124-131, https://doi.org/10.7324/JAPS.2016.601017.

53. Tahvilian, R.; Ebrahimi, A.; Beiki, O.; Nemati, H.; Masoud, S. Preparation and clinical evaluation of finastride gel in the treatment of idiopathic Hirsutism. J. Drug Assess. 2015, 4, 12-18, https://doi.org/10.3109/21556660.2015.1056525.

54. Tsanaktsidou, E.; Karavasili, C.; Zacharis, C.K.; Fatouros, D.G.; Markopoulou, C.K. Partial least square model (PLS) as a tool to predict the diffusion of steroids across artificial membranes. Molecules 2020, 25, 1387-1403, https://doi.org/10.3390/molecules25061387.

55. Sánchez, A.B.; Calpena, A.C.; Mallandrich, M.; Clares, B. Validation of an Ex vivo permeation method for the intestinal permeability of different BCS drugs and its correlation with caco-2 in vitro experiments. Pharmaceutics 2019, 11, 638-650, https://doi.org/10.3390/pharmaceutics11120638.

56. Tran, T.T.; Tran, P.H. Controlled release film forming systems in drug delivery: the potential for efficient drug delivery. Pharmaceutics 2019, 11, https://doi.org/10.3390/pharmaceutics11060290. 
57. Ahmed, I.S.; Rashed, H.M.; Fayez, H.; Farouk, F.; Shamma, R.N. Nanoparticle-mediated dual targeting: An approach for enhanced baicalin delivery to the liver. Pharmaceutics 2020, 12, https://doi.org/10.3390/pharmaceutics12020107.

58. Silveira, E.F.; Rannier, L.; Nalone, L.; da Silva, C.F.; Chaud, M.V.; Barbosa, R.D.; Junior, R.L.; da Costa, L.P.; Souto, E.B.; Severino, P. Loading of 5-aminosalicylic in solid lipid microparticles (SLM). J. Therm. Anal. Calorim. 2020, 139, 1151-1159, https://doi.org/10.1007/s10973-019-08544-7.

59. Ahmad, I.; Pandit, J.; Sultana, Y.; Mishra, A.K.; Hazari, P.P.; Aqil, M. Optimization by design of etoposide loaded solid lipid nanoparticles for ocular delivery: characterization, pharmacokinetic and deposition study. Mater. Sci. Eng. C. 2019, 100, 959-970, https://doi.org/10.1016/j.msec.2019.03.060.

60. Dara, T.; Vatanara, A.; Meybodi, M.N.; Vakilinezhad, M.A.; Malvajerd, S.S.; Vakhshiteh, F.; Shamsian, A.; Sharifzadeh, M.; Kaghazian, H.; Mosaddegh, M.H. Erythropoietin-loaded solid lipid nanoparticles: Preparation, optimization, and in vivo evaluation. Colloids Surf. B. 2019, 178, 307-316, https://doi.org/10.1016/j.colsurfb.2019.01.027.

61. Yasir, M.; Chauhan, I.; Zafar, A.; Verma, M.; Noorulla, K.M.; Tura, A.J.; Alruwaili, N.K.; Haji, M.J.; Puri, D.; Gobena, W.G.; Dalecha, D.D. Buspirone loaded solid lipid nanoparticles for amplification of nose to brain efficacy: Formulation development, optimization by Box-Behnken design, in-vitro characterization and in-vivo biological evaluation. J. Drug Deliv. Sci. Technol. 2020, 61, https://doi.org/10.1016/j.jddst.2020.102164.

62. Nasiri, F.; Faghfouri, L.; Hamidi, M. Preparation, optimization, and in-vitro characterization of $\alpha-$ tocopherol-loaded solid lipid nanoparticles (SLNs). Drug Dev. Ind. Pharm. 2020, 46, 159-171, https://doi.org/10.1080/03639045.2019.1711388.

63. Rostamkalaei, S.S.; Akbari, J.; Saeedi, M.; Morteza-Semnani, K.; Nokhodchi, A. Topical gel of Metformin solid lipid nanoparticles: A hopeful promise as a dermal delivery system. Colloids Surf. B. 2019, 175, 150157, https://doi.org/10.1016/j.colsurfb.2018.11.072.

64. Hanif, M.; Khan, H.U.; Afzal, S.; Majeed, A.; Iqbal, N.; Afzal, K.; Andleeb, M.; Rauf, A.; Farooq A. Formulation, characterization and optimization of nebivolol-loaded sustained release lipospheres. Trop. J. Pharm. Res. 2019, 18, 223-231, https://doi.org/10.4314/tjpr.v18i2.2.

65. Kang, J.H.; Chon, J.; Kim, Y.I.; Lee, H.J.; Oh, D.W.; Lee, H.G.; Han, C.S.; Kim, D.W.; Park, C.W. Preparation and evaluation of tacrolimus-loaded thermosensitive solid lipid nanoparticles for improved dermal distribution. Int. J. Nanomedicine 2019, 14, 5381-5396, https://doi.org/10.2147/IJN.S215153.

66. López-Iglesias, C.; Quílez, C.; Barros, J.; Velasco, D.; Alvarez-Lorenzo, C.; Jorcano, J.L.; Monteiro, F.J.; García-González, C.A. Lidocaine-loaded solid lipid microparticles (SLMPs) produced from gas-saturated solutions for wound applications. Pharmaceutics 2020, 12, https://doi.org/10.3390/pharmaceutics12090870.

67. Amasyaa, G.; Aksub, B.; Badillia, U.; Onay-Besikcic, A.; Tarimcia, N. QbD guided early pharmaceutical development study: Production of lipid nanoparticles by high pressure homogenization for skin cancer treatment. Int. J. Pharm. 2019, 563, 110-121, https://doi.org/10.1016/j.ijpharm.2019.03.056.

68. Mitri, K.; Shegokar, R.; Gohla, S.; Anselmi, C.; Müller, R.H. Lipid nanocarriers for dermal delivery of lutein: preparation, characterization, stability and performance. Int. J. Pharm. 2011, 414, 267-275, https://doi.org/10.1016/j.ijpharm.2011.05.008.

69. Momoh, M.A.; Kenechukwu, F.C.; Attama, A.A. Formulation and evaluation of novel solid lipid microparticles as a sustained release system for the delivery of metformin hydrochloride. Drug Deliv. 2013, 20, 102-111, https://doi.org/10.3109/10717544.2013.779329.

70. Dasgupta, S.; K Ghosh, S.; Ray, S.; Mazumder, B. Solid lipid nanoparticles (SLNs) gels for topical delivery of aceclofenac in vitro and in vivo evaluation. Curr. Drug Deliv. 2013, 10, 656-666, https://doi.org/10.2174/156720181006131125150023.

71. Madan, J.R.; Khude, P.A.; Dua, K. Development and evaluation of solid lipid nanoparticles of mometasone furoate for topical delivery. Int. J. Pharm. Investig. 2014, 4, 60-65.

72. Gujjar, S.; Madhavi BLR.; Karki, R. Formulation and Evaluation of topical gel containing nanostructured lipid carriers dispersion of an antifungal drug. Acta Pharm. Sci. 2019, 57, 57-75, https://doi.org/10.23893/1307-2080.APS.05724.

73. Raina, H.; Kaur, S.; Jindal, A.B. Development of efavirenz loaded solid lipid nanoparticles: Risk assessment, quality-by-design (QbD) based optimisation and physicochemical characterisation. J. Drug Deliv. Sci. Tec. 2017, 39, 180-191, https://doi.org/10.1016/j.jddst.2017.02.013.

74. Vaghasiya, H.; Kumar, A.; Sawant, K. Development of solid lipid nanoparticles based controlled release system for topical delivery of terbinafine hydrochloride. Eur. J. Pharm. Sci. 2013, 49, 311-322, https://doi.org/10.1016/j.ejps.2013.03.013.

75. Gupta, S.; Wairkar, S.; Bhatt, L.K. Isotretinoin and $\alpha$-tocopherol acetate-loaded solid lipid nanoparticle topical gel for the treatment of acne. J. Microencapsul. 2020, 37, 557-565, https://doi.org/10.1080/02652048.2020.1823499. 